DOI: $10.24850 /$ j-tyca-2020-05-02

Artículos

\title{
Gestión hídrica y educación ambiental como facilitadores del desarrollo turístico sustentable en Valladolid, Yucatán
}

\section{Water management and environmental education as facilitators of sustainable tourism development in Valladolid, Yucatan}

Grisel Cervantes-Cocom ${ }^{1}$, ORCID: https://orcid.org/0000-0001-75434004

Camilo Gabriel Chan-Ceh², ORCID: https://orcid.org/0000-0001-89627683

${ }^{1}$ Tecnológico Nacional de México, Instituto Tecnológico Superior de Valladolid, Valladolid, Yucatán, México, grisel.cc@valladolid.tecnm.mx 2Tecnológico Nacional de México, Instituto Tecnológico Superior de Valladolid, Valladolid, Yucatán, México, camilo.cc@valladolid.tecnm.mx

Autora para correspondencia: Grisel Cervantes-Cocom, grisel.cc@valladolid.tecnm.mx 


\section{Resumen}

Con la información obtenida de dos empresas de giro turístico, cuyo principal atractivo es el uso recreativo de cenotes, se analizaron las características de usos, consumos, costos y requisitos legales en materia ambiental. Aunado a esto, se realizó un estudio experimental de educación ambiental con los trabajadores de las empresas en los dominios de conocimiento, gestión y conciencia ambiental. El objetivo fue diagnosticar la gestión del recurso hídrico y el nivel de educación ambiental para elaborar una propuesta de mejora. Los resultados obtenidos para el estudio experimental demostraron que el nivel de educación ambiental tuvo una diferencia estadística significativa entre las puntuaciones obtenidas antes y después de la impartición del taller a los trabajadores elegidos de manera aleatoria. El taller se estableció de acuerdo con el análisis de probabilidades entre cada una de las clasificaciones del nivel de educación ambiental que, como resultado, no fueron las mismas. Debido a que el mayor porcentaje de los empleados se ubicó en básico, el taller se impartió a partir de ese nivel. La propuesta a implementar en las empresas fue cambiar su sistema de almacenamiento de aguas en tanques o fosas sépticas por pequeñas plantas de tratamiento biológico. En última instancia, se recomendaron fosas sépticas, implementando un tratamiento oxidativo. Para hacer más eficiente el consumo de agua, se sugirió el uso de tecnología ahorradora, todo tipo de anuncios que motiven al ahorro de agua, campañas de concientización para los trabajadores y políticas ambientales. 
Palabras clave: educación ambiental, gestión, recurso hídrico, conciencia ambiental, conocimiento ambiental.

\section{Abstract}

With the information obtained from two tourist companies whose attraction is the recreational use of cenotes, the characteristics of use, consumption, costs and legal requirements in environmental matters were analyzed. In addition to this, an experimental environmental education study was carried out for company workers in the domains of knowledge, management and environmental awareness. The objective was to diagnose the management of the water resource and the level of environmental education, to make a proposal for improvements. The results obtained for the experimental study showed that the level of environmental education had a significant statistical difference between the scores obtained before and after the delivery of the workshop to the workers chosen at random. The workshop was established according to the analysis of probabilities between each of the classifications of the level of environmental education that as a result these were not the same and because the highest percentage of employees was located at the basic level; the workshop was given to from this level. The proposal to implement in the companies was to change their water storage system in tanks or septic tanks by small biological treatment plants. Ultimately, septic tanks were recommended along with an oxidative treatment. To make water consumption more efficient, we recommend the use of energy-saving technology, all kinds of advertisements that motivate 
water saving, awareness campaigns for workers and environmental policies.

Keywords: Environmental education, management, water resources, environmental awareness, environmental knowledge.

Recibido: 06/10/2019

Aceptado: 07/01/2020

\section{Introducción}

La naturaleza kárstica del suelo en la península de Yucatán, México, permite la infiltración del agua. Es por ello que a lo largo de miles de años se han originado cenotes, formaciones de gran belleza natural y proveedores del recurso hídrico por generaciones. Sin embargo, las características del suelo y profundidad no sólo permiten la captación del agua, sino también la fácil percolación de contaminantes. Así, es deseable el disfrute moderado de los recursos, lo que se traduce en la necesidad 
de implementar métodos de gestión adecuados en materia de agua. El turismo genera una derrama económica invaluable, que se traduce en beneficios a la población; pero también puede significar alto consumo de recursos y alteración fisicoquímica de los mismos al ser una actividad antrópica. Por tanto, la gestión adecuada del recurso permite disminuir los impactos ambientales.

En Valladolid, Yucatán, ubicado al sureste de México, específicamente en el oriente del estado de Yucatán, con las siguientes coordenadas geográficas: latitud, $20^{\circ} 41^{\prime} 22^{\prime \prime} \mathrm{N}$ y longitud, $88^{\circ} 12^{\prime} 6^{\prime \prime} \mathrm{W}$, existen cenotes dispuestos en concesión y asignación para uso recreativo. Sin embargo, cuando se acude a estos sitios hay incertidumbre sobre la calidad del agua, pues la disposición inadecuada de las aguas residuales, es decir, dispuestas sin tratamiento previo, es una gran preocupación en la zona.

Un turista puede llegara generar entre 700 y 800 gramos de basura por día. Esto origina un total aproximado de $1164 \mathrm{~kg} /$ día de acuerdo con el promedio de visitantes; un promedio mensual de residuos de 34920 $\mathrm{kg}$; un gasto energético elevado, y aguas residuales que pueden superar los 200 litros por turista, dependiendo de la carga hotelera en Valladolid (Sefotur \& UADY, 2013).

Lo anterior demuestra la relevancia de la gestión y educación ambiental en el sector turístico. Por lo tanto, se contempla la educación ambiental como herramienta de mitigación y este estudio se planteó reconociéndola como el proceso sistemático para generar conocimientos que forman una conciencia de cambio en los individuos, a fin de lograr 
una conciencia armónica con el medio ambiente, y así contribuir en la tarea de proteger el entorno y evitar dañar a los ecosistemas (Palos, 2005).

Así, la situación actual del turismo en materia ambiental debe ser caracterizada y actualizada, con el propósito de presentar herramientas que le permitan al sector cubrir los requisitos legales vigentes en materia ambiental y estar preparados ante el auge de proyectos estratégicos que detonarán el desarrollo regional sustentable.

Con esto en mira, el fin del presente estudio fue realizar un diagnóstico de la gestión del recurso hídrico y el nivel de educación ambiental para realizar una propuesta de mejora. También, fue posible observar la concordancia existente entre el nivel de educación ambiental de los trabajadores y el desempeño ambiental de las empresas.

Se presentan los requisitos legales que en general debían cumplir las empresas evaluadas del sector turístico, al igual que los consumos de agua, costos y características de uso que las describen. Igualmente, se muestran como resultados el nivel de conocimiento ambiental, gestión ambiental y conciencia ambiental de los trabajadores. Este último de gran importancia, pues se enfoca en comprender el daño ambiental que se genera debido a la incorrecta disposición o manejo de residuos, y mejorar la actitud hacia el desarrollo sustentable.

A partir del presente proyecto se analizó el manejo del recurso hídrico para minimizar el impacto ambiental, específicamente en paraderos turísticos con cenotes para uso recreativo, que lograron establecer políticas ambientales viables. El diagnóstico además permitió 
diseñarun taller de educación ambiental en un nivel básico, impartido con éxito a los trabajadores.

Conjuntamente las actividades realizadas durante la investigación contribuyeron a mejorar el nivel de educación ambiental, constatado en los resultados estadísticos del estudio experimental. Así, lo trascendental del presente proyecto se debe a que anteriormente no se tenía documentado estudio alguno en Valladolid sobre el manejo del agua y su impacto sobre la calidad del recurso, por lo que se considera un trabajo que puede ayudar al sector turístico involucrado en mejorar su desempeño ambiental, coadyuvando a la sustentabilidad y, sobre todo, al mejoramiento de la salud pública.

\section{Materiales y métodos}

\section{Tipo de investigación}


En general, la investigación fue de enfoque mixto, abordando dos vertientes: diagnóstico del manejo del recurso hídrico y educación ambiental en dos empresas turísticas, con las cuales se firmó un convenio en el que las empresas se comprometían a facilitar la documentación solicitada, permitir la aplicación de instrumentos e impartición del taller de educación ambiental; todo lo anterior condicionado al compromiso de mantener la confidencialidad de las compañías.

El proyecto se llevó a cabo a lo largo de un año, pero el trabajo de campo y aplicación de instrumentos tuvo una duración de cinco meses.

En cuanto a la investigación para integrar un diagnóstico de la gestión del agua en el sector turístico local, se asumió un enfoque cualitativo, debido a que se exploró el fenómeno de la gestión hídrica a profundidad; es decir, se evaluaron las deficiencias mediante instrumentos de investigación y una actividad que simuló una auditoría ambiental, con el fin de proponer soluciones.

Una vez contextualizados e interpretados los datos recabados, se formularon propuestas para la gestión adecuada del recurso hídrico, con el objetivo de minimizar los volúmenes e impacto de la descarga de aguas residuales. Por lo tanto, la recolección de los datos se llevó a cabo en el escenario natural, en este caso las empresas, que dependieron directamente de los individuos que se entrevistaron o proporcionaron la información. Así, realizar un estudio cualitativo ayudó a conocer el contexto y escenario de la problemática.

Parte de esta investigación, enfocada a la educación ambiental para empresas del sector turístico, presentó un enfoque cuantitativo. Con la 
finalidad de explicar la correspondencia al carácter cuantitativo es preciso mencionar que se aplicó una encuesta que integró ítems que permitieron estandarizary agrupar la información, lo que a su vez admitiría el manejo de datos y resultados con características numéricas y estadísticas. Los resultados fueron dependientes de las particularidades de los trabajadores, por ende, sometidas a la variación de las actividades del personal o afluencia turística, lo que desembocó en un estudio con diseño cuantitativo.

\section{Instrumentos}

Para realizar una indagación inicial se empleó la entrevista personal a profundidad como una herramienta de obtención inmediata de información; se aplicó al gerente general y al jefe de mantenimiento de cada empresa. Este instrumento se empleó con el objetivo determinar áreas específicas en las que se consumen los volúmenes de agua, actividades, personal y afluencia turística involucrada en las actividades de uso. Posterior a la entrevista de exploración, se reformuló un instrumento para la caracterización, clasificación y cuantificación de costos y volúmenes basado en el trabajo presentado por Viñuales, 
Tecnología y

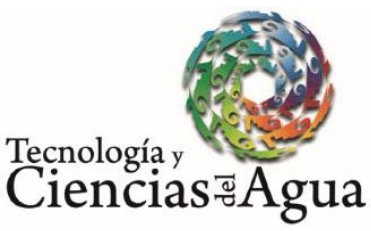

2020, Instituto Mexicano de Tecnología del Agua

Open Access bajo la licencia CC BY-NC-SA 4.0

(https://creativecommons.org/licenses/by-nc-sa/4.0/)

Fernández y González (2001). Este instrumento permitió al estudio adaptarse a los trabajos de la empresa, y restricciones de tiempo, espacio y acceso. Debido a que es comprensible que las empresas no proporcionan información indiscriminadamente y mucho menos afectando sus actividades, se realizaron visitas tuteladas y se empleó documentación autorizada. En este punto, los dos paraderos proporcionaron información de manera confidencial, lo que ayudó a estructurar la matriz de requisitos legales ambientales. Dichos instrumentos permitieron diagnosticar aspectos de la gestión ambiental y legal de las compañías.

Para evaluar la educación ambiental se aplicó una encuesta que incluyó ítems en tres secciones o categorías: conocimiento, conciencia y gestión en el carácter ambiental; reformulado a un carácter cuantitativo - a diferencia de Palos (2010)_, pero con base en los dominios que Palos (2010) presenta en su estudio acerca de educación ambiental.

Los ítems que se plantearon buscaban determinar, en general, el nivel de educación ambiental de los trabajadores, así como sus características o datos demográficos. Se obtuvo información acerca de edad, género, nivel educativo y el tipo de labor en la empresa.

Se utilizó la escala de Likert. Las categorías mencionadas incluyeron 10 preguntas con un mismo enfoque $y$, a su vez, con cinco posibles respuestas asignadas a un valor numérico con respecto a cada pregunta: $1=$ nunca; 2 casi nunca; $3=$ a veces; $4=$ casi siempre; $5=$ siempre; y también $5=$ nunca; 4 = casi nunca; $3=$ a veces; 2 = casi siempre; 1 = siempre. Así, la persona encuestada pudo seleccionar de acuerdo con 
su criterio. El puntaje para cada categoría fue de 50 como máximo y 0 como mínimo. Con base en el valor del puntaje obtenido se establecieron cinco niveles: malo < 20); insuficiente de 21 a 28; regular de 29 a 36; bueno de 37 a 44, y excelente de 45 a 50. Este tipo de cuestionario permitió realizar los análisis estadísticos.

El análisis de la educación ambiental con enfoque cuantitativo fue de carácter experimental. A partir del diagnóstico del estado de la educación de los trabajadores, se desarrolló un taller, con el objetivo de subsanar las deficiencias detectadas y, por último, determinar la diferencia entre el nivel inicial y el posterior a la impartición del taller en las empresas.

\section{Confiabilidad y validez del instrumento}

La validez del instrumento, de acuerdo con la fuente (Palos, 2010) fue sometida a juicio de expertos; de igual forma, una vez reformulada la encuesta, se sometió a juicio. Los test o instrumentos para determinar el nivel de educación ambiental usados con fines de investigación deben evidenciar su fiabilidad. En este estudio se utilizó el análisis de alfa de Cronbach, resultando un valor de 0.86 , un coeficiente de alfa > a 0.8 ; por lo tanto, el criterio de fiabilidad del instrumento es bueno. El valor mínimo 
aceptable del alfa de Cronbach es 0.7 ; por debajo de ese valor, la consistencia interna de la escala utilizada es baja (Celina \& Campo, 2005).

\section{Procedimientos}

Al caracterizar los usos del agua de los paraderos turísticos —una vez obtenida la información mediante la encuesta preliminar- se implementaron posteriormente los ajustes necesarios, y se realizó la caracterización de los volúmenes y costos de consumo de agua.

A continuación, para tener un diagnóstico basado en la metodología de auditorías ambientales - a fin de observar la gestión del agua en el sector turístico-, se realizó una recopilación de la legislación en materia de agua en los ámbitos federal, estatal y municipal. Entonces, se categorizó la información, y se seleccionaron las leyes y reglamentos aplicables a paraderos turísticos. Una vez concluido el proceso de discriminación y selección, se formuló y estructuró la lista de verificación general, que se aplicó en los paraderos, previo aviso.

Durante la simulación de la auditoría, el gerente general o encargado de la empresa proporcionó la información o evidencia para sustentar el cumplimiento de la legislación ambiental en materia de agua. A partir de la información recopilada y categorizada, se hizo la matriz de 
requisitos legales, cuya importancia radica en la descripción puntual del rubro o fracción correspondiente a una norma, ley o reglamento, para las cuales, si se cumplen, se deben presentar evidencias.

Por último, para crear conciencia sobre el uso racional del agua y generación de residuos, se socializó la información a las empresas que participaron en el proyecto de investigación. Así, se llevaron a cabo reuniones de trabajo para presentar los objetivos y procedimientos a seguir en materia de educación ambiental debido a que esta actividad fue dependiente de una interacción directa con los trabajadores.

Para diseñar la encuesta y determinar el nivel de educación ambiental y, además, conocer las características demográficas de los trabajadores, se estructuraron preguntas enfocadas en tres categorías, aplicadas de manera aleatoria. Se comprobó la confiabilidad del instrumento y se procedió a elaborar la versión final. Por su puesto, el entrenamiento del encuestador fue primordial antes de la aplicación.

El análisis de los resultados permitió describir las características de los trabajadores en materia de educación, que inciden en el desempeño ambiental.

Se generaron parámetros descriptivos y se estableció la relación de probabilidad de ocurrencia en los niveles (malo, insuficiente, regular, bueno y excelente) de las secciones conocimiento, gestión y conciencia ambiental de las empresas.

A la postre, se diseñó el modelo del taller de educación ambiental para las empresas turísticas en cuestión y se procedió a una nueva evaluación del conocimiento ambiental de los trabajadores. El taller de 
educación ambiental tuvo una duración de tres semanas; con dos sesiones de dos horas por semana, en promedio, esto de acuerdo con la disposición de los trabajadores.

Durante el taller se expusieron, mediante recursos digitales y didácticos, conceptos como medio ambiente, contaminación y conciencia ambiental. También se explicó y ejemplificó la clasificación de residuos sólidos, reciclaje, ahorro de energía, residuos peligrosos, etiquetado, legislación y gestión. Por último, se implementaron actividades lúdicas y de mesa-panel para intercambio de opiniones y recomendaciones de los trabajadores, en las que se destacaron las implicaciones ambientales de Valladolid. Se diseñaron y aplicaron análisis a las variables; se establecieron los parámetros descriptivos, y un análisis inferencial comparativo del antes y después del taller de educación ambiental. El procesamiento de los datos obtenidos se llevó a cabo mediante el programa estadístico SPSS versión 24.

\section{Resultados}

\section{Caracterización del uso y volúmenes de consumo}


Durante la verificación de la disposición de efluentes sanitarios de los paraderos turísticos se observó que el paradero uno cuenta con un tanque de almacenamiento, que es vaciado de manera periódica en el relleno sanitario de la ciudad; el paradero dos tiene fosa séptica (nombrados numéricamente por confidencialidad).

Las actividades de limpieza que se realizan en los paraderos son lavado de pisos, trastes, utensilios de cocina y baños. Además, la limpieza de mesas y sillas para la comodidad de los clientes se realiza a diario.

El paradero turístico uno usa agua de pozo para todas sus actividades; el paradero dos consume agua proporcionada por el sistema de agua potable y alcantarillado.

Durante la observación de las actividades de trabajo en los cenotes no se detectaron acciones específicas para la prevención de contaminación ni el reúso de volúmenes de agua. Sin embargo, posterior a la verificación, se colocaron tanques de descarga en los baños con menores volúmenes; en específico, se cambiaron los de 9 a 6 litros de capacidad. Así, la disposición de colaborar fue visible e indispensable para la ejecución del proyecto e implementación de actividades correctivas.

En la península de Yucatán existe gran cantidad de cenotes con uso turístico. Las percepciones, actitudes, expectativas y comportamientos ante las circunstancias ambientales dan forma a diferentes usos y manejo (Moser, Navarro, Ratiu, \& Weiss, 2010) de los cenotes. Por lo tanto, la 
primera etapa de este estudio fue dedicado al diagnóstico del consumo y manejo del recurso hídrico; pero la falta de conciencia sobre lo que implica la contaminación del agua para la salud propicia un uso indiscriminado de productos en las actividades de limpieza en general. Los resultados del consumo de los dos paraderos se presentan en la Figura 1 y Figura 2 . De esta forma, aplicar los instrumentos para la determinación de los volúmenes de consumo en el paradero con abastecimiento de agua de pozo en la Figura 1 arrojó que el consumo bimestral promedio del paradero es de unos 40000 litros, tomando en cuenta que es un paradero que presta sus servicios a un número reducido de personas por día, el consumo es moderado. 
Tecnología y

\section{Ciencias $\approx$ Agua}

2020, Instituto Mexicano de Tecnología del Agua

Open Access bajo la licencia CC BY-NC-SA 4.0

(https://creativecommons.org/licenses/by-nc-sa/4.0/)

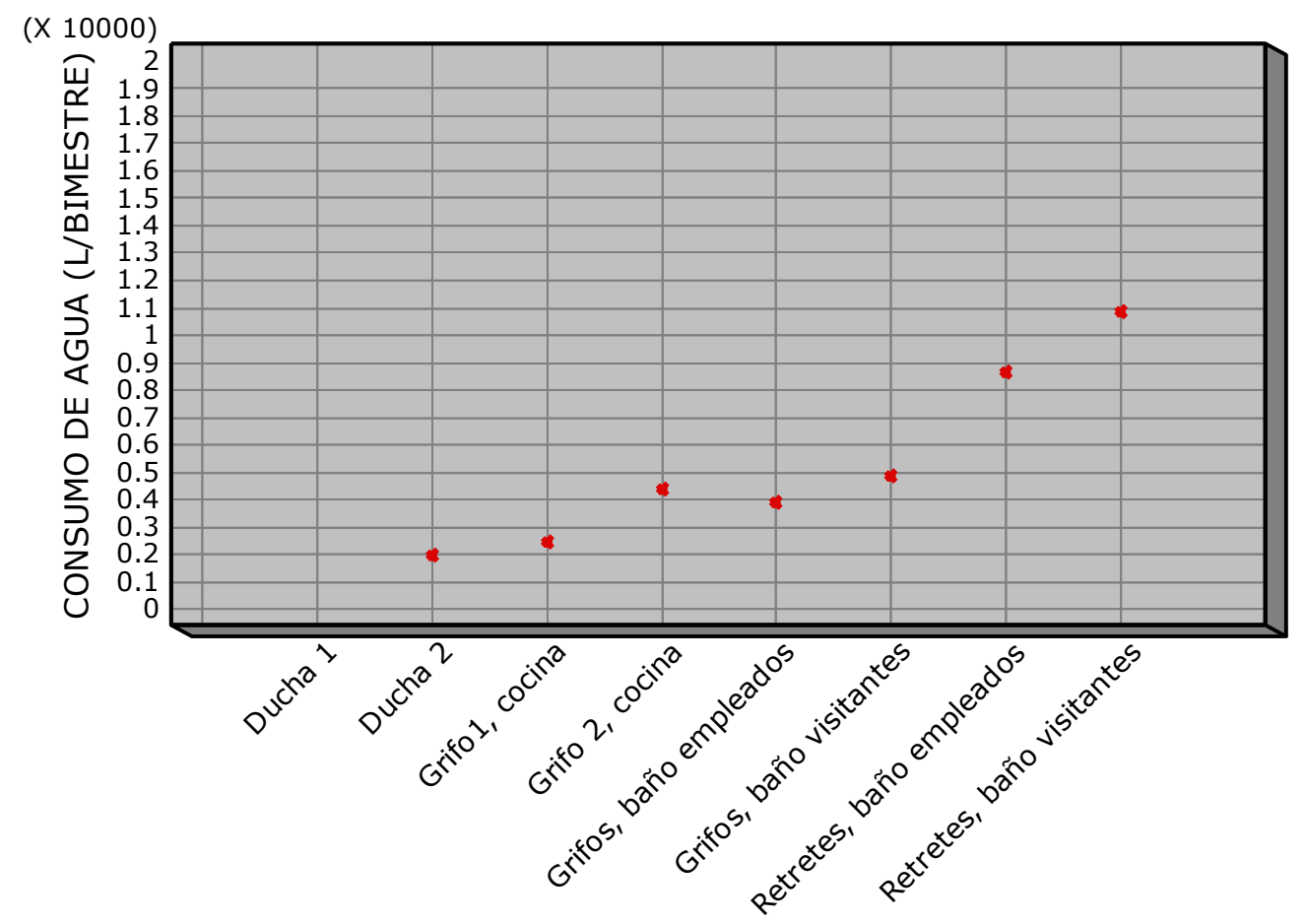

PUNTOS DE USO DE AGUA

Figura 1. Dispersión de consumo de agua en paradero turístico uno, con abastecimiento de agua de pozo. Fuente: elaboración propia. Nota: la ducha 1 tiene consumo de 120000 l/bimestre. 
Teçnología y

Ciencias $₫$ Agua
2020, Instituto Mexicano de Tecnología del Agua

Open Access bajo la licencia CC BY-NC-SA 4.0

(https://creativecommons.org/licenses/by-nc-sa/4.0/)

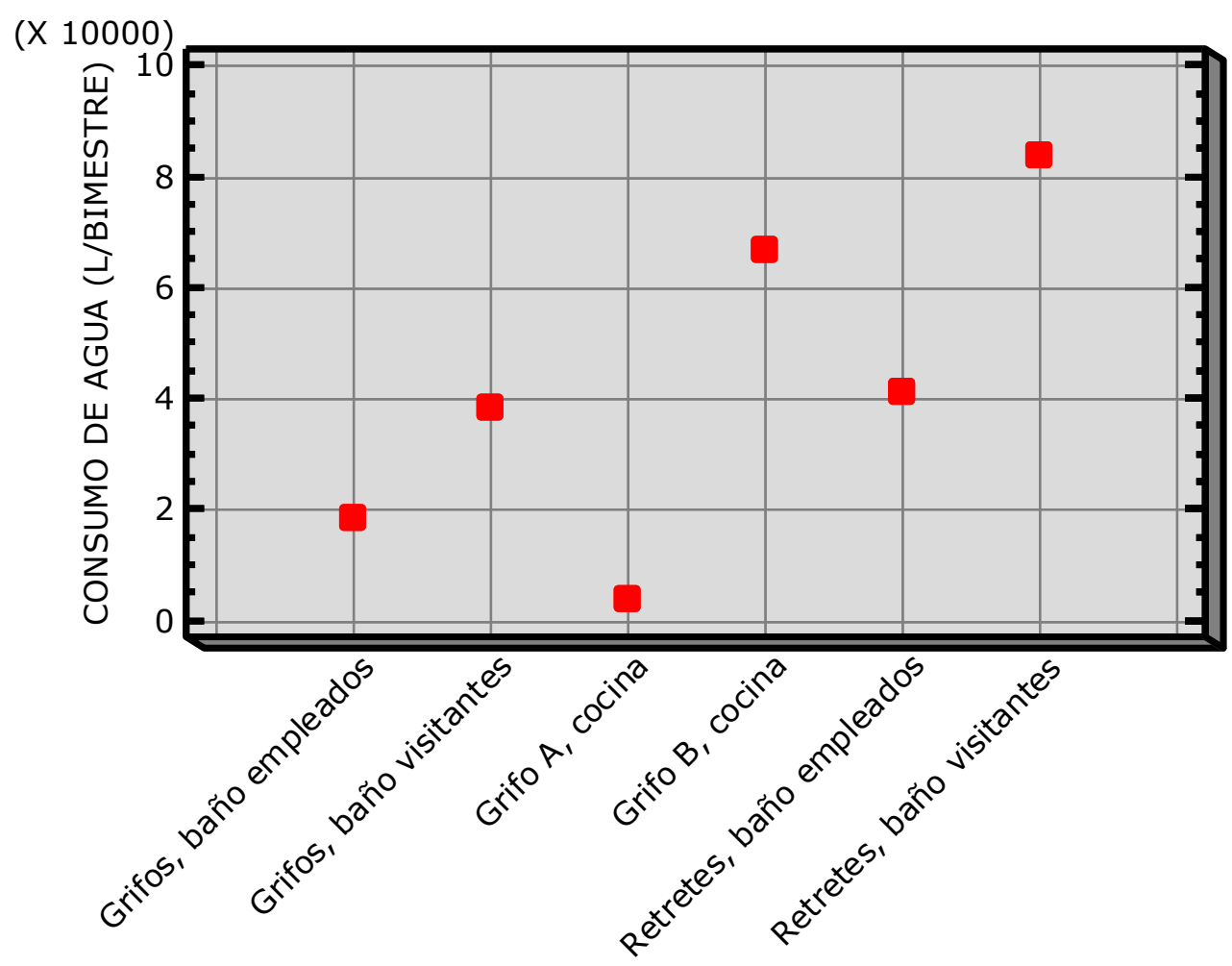

PUNTOS DE USO DE AGUA

Figura 2. Dispersión de consumo de agua en paradero turístico dos, con abastecimiento de agua potable. Fuente: elaboración propia.

El paradero con abastecimiento de agua potable consume alrededor de 245000 litros por bimestre, distribuido en ocho puntos de uso de agua, como se observa en la Figura 2, detectado para una afluencia de 100 personas en promedio (en temporada baja) que acuden a las actividades recreativas. La cantidad de usuarios de los servicios y volúmenes de consumo de agua sirvió de referencia para indagar qué sistema de disposición o tratamiento de agua era más conveniente. 
Para el paradero con abastecimiento de agua de pozo con 40000 litros de consumo, el sistema de disposición fue la fosa séptica, pues no recibe más de 10 a 15 personas por día.

En el paradero con abastecimiento de agua potable se hizo la recomendación de la instalación de una planta de tratamiento de aguas residuales, pues la fosa séptica no es útil para más de 100 usuarios que se registran por día.

La disminución de los costos de consumo hídrico es motivo para implementaractividades de reducción o reutilización de agua. En la Figura 3 se muestra el costo bimestral de seis puntos de uso de agua en el paradero con sistema de abastecimiento de agua potable, siendo el total del monto de costo bimestral de $\$ 2386.62$ pesos. 
Tecnología y

Ciencias $₫$ Agua
2020, Instituto Mexicano de Tecnología del Agua

Open Access bajo la licencia CC BY-NC-SA 4.0

(https://creativecommons.org/licenses/by-nc-sa/4.0/)

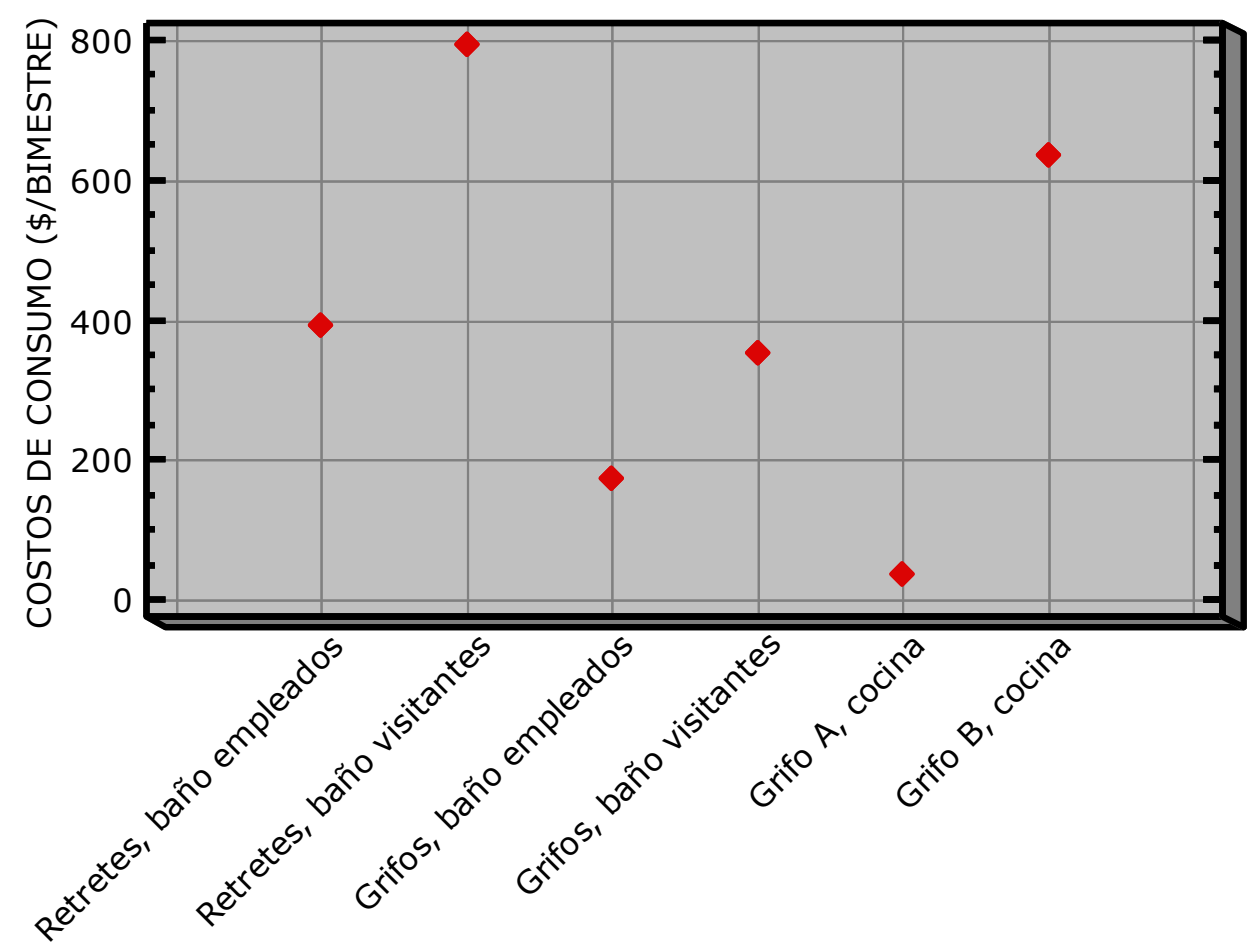

PUNTOS DE USO DE AGUA

Figura 3. Dispersión de costos de paradero turístico dos con sistema de abastecimiento de agua potable. Fuente: elaboración propia.

En la Figura 4 se observan los puntos de uso del agua para el paradero con abastecimiento de agua de pozo. El costo mayoritario se debe a los volúmenes superiores a 12000 litros consumidos en las duchas. Así, el coste asciende a \$3 254.54 pesos por bimestre en temporada baja. Cabe destacar que posterior a las actividades de verificación se implementarían actividades de reúso y disminución de consumo; por ejemplo, la captación del agua de las duchas y de la piscina, 
Tecnología y

Ciencias $\approx$ Agua
2020, Instituto Mexicano de Tecnología del Agua

Open Access bajo la licencia CC BY-NC-SA 4.0

(https://creativecommons.org/licenses/by-nc-sa/4.0/)

para llevar el agua a tanques de almacenamiento y reutilizarla en la descarga de los retretes de los baños.

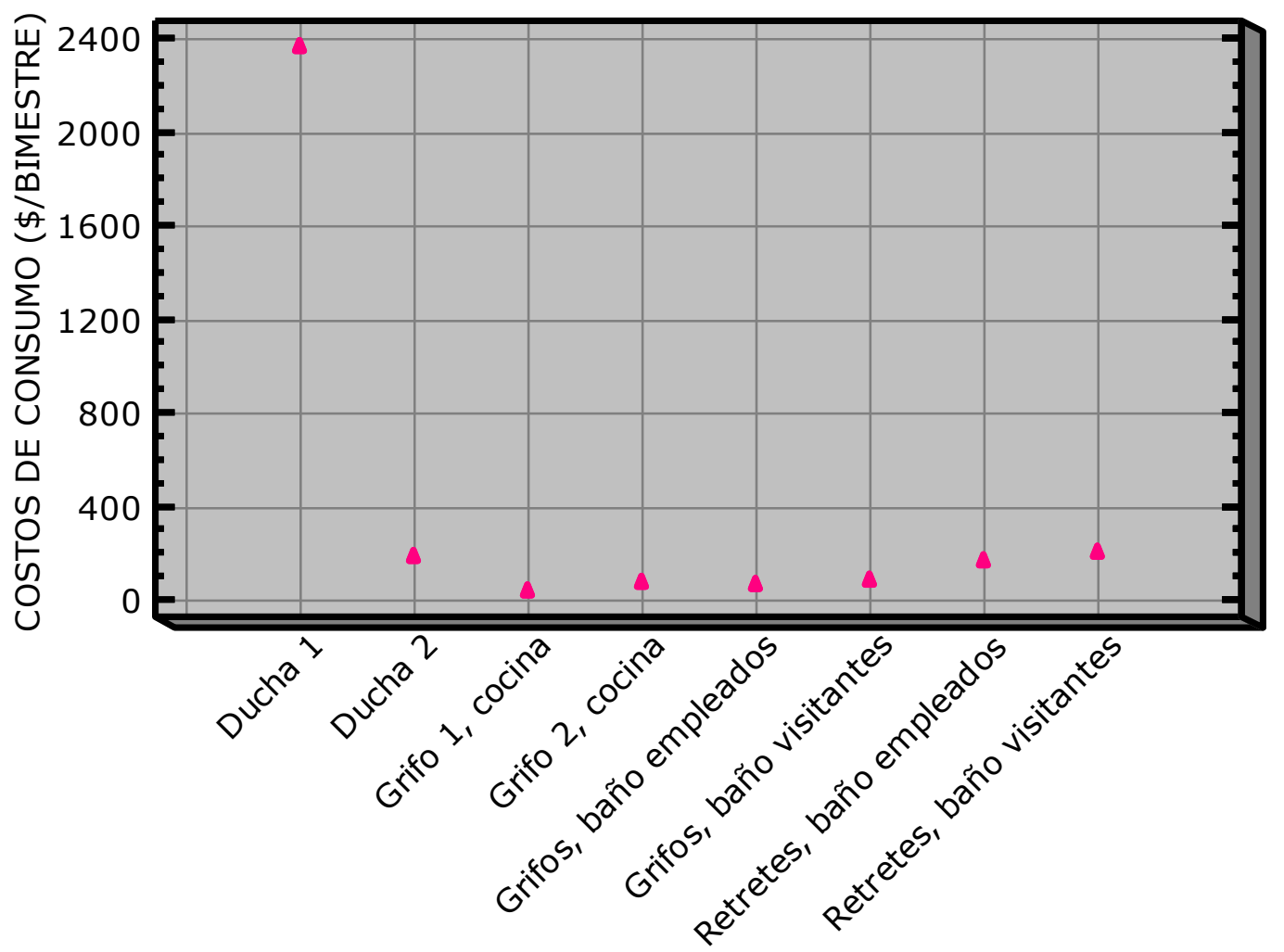

PUNTOS DE USO DE AGUA

Figura 4. Dispersión de costos en paradero turístico uno, con abastecimiento de agua de pozo. Fuente: elaboración propia.

\section{Educación ambiental}


Los resultados se presentan en dos niveles de análisis: descriptivo e inferencial. El paradero dos, con abastecimiento de agua potable; el paradero uno, con abastecimiento de agua de pozo.

En cuanto al análisis descriptivo, se desplegó de acuerdo con los dominios o categorías que se presentaron en la encuesta.

Con respecto al análisis inferencial, fue comparativo de los resultados anteriores y posteriores con base en cada dominio, y en general.

\section{Resultados descriptivos anteriores a la capacitación ambiental}

Para llevar a cabo la capacitación fue indispensable diagnosticar previamente a las empresas, a fin de ofrecer un taller de acuerdo con las características de los trabajadores. Los resultados de los análisis descriptivos indican que la mayoría de los elementos que componen la escala se caracterizan por tener una variabilidad distribuida en las cinco posibles opciones de respuesta (de $1=$ nunca a $5=$ siempre). De los resultados descriptivos destaca lo siguiente: 
- Existe una distribución equilibrada en la proporción de edad de los trabajadores: de 18 a 22, de 23 a 27, de 28 a 32 y de 38 o más ( $20 \%$ o más); con excepción del rango de edad de 33 a 37 años, que tuvo menor porcentaje ( $8 \%)$.

- La contratación y presencia de hombres y mujeres es de 52 y $48 \%$, respectivamente; esto obedece a que existe igualdad laboral de puestos para ambos géneros y no es marcada la diferencia porcentual entre hombres y mujeres.

- El $74 \%$ de los trabajadores tiene un nivel educativo de secundaria o preparatoria; por lo general se desempeña como cocinero, camarero, técnico o ayudante. El $20 \%$ con licenciatura labora como recepcionista o técnico. El $7 \%$ tiene nivel primaria; 37\%, secundaria; 36\%, preparatoria.

- En cuanto al estado civil, $50 \%$ es soltero. Al $48 \%$ de los trabajadores se le asignan tareas variadas de acuerdo con la temporada y necesidades de las empresas, por lo que se les considera ayudantes.

- A la frase: "Tengo conocimiento de las sustancias y materiales contaminantes que se generan debido a las actividades de mantenimiento, limpieza, cocina o servicio", 49\% de los sujetos está entre los niveles de nunca, casi nunca y a veces, lo que supone un elevado porcentaje de indiferencia hacia tal circunstancia.

- El $78 \%$ afirma que mientras labora cuida recursos, como agua y luz.

- El $65 \%$ de los trabajadores de las empresas siempre o casi siempre realiza actividades para el cuidado de los recursos en el hogar.

- Una gran mayoría de los trabajadores (67\% entre siempre, casi siempre y a veces) deja conectados aparatos electrodomésticos. 
- El 52\% siempre percibe basura tirada mientras camina por la ciudad. Pero sólo $29 \%$ es partidario de colaborar en campañas o programas de conservación ambiental.

- Sólo $15 \%$ de los trabajadores se preocupa por separar la basura; mientras que $61 \%$ nunca, casi nunca o a veces la separa.

- Los trabajadores están conscientes sobre el daño ambiental debido al uso de aerosoles, pero el 15\% siempre los usa.

- El $50 \%$ considera que la cantidad de basura generada siempre es un tema relevante debido a su disposición.

- Nunca, casi nunca y a veces respondió un 76\% a la afirmación "uso productos reciclados". Entre los que siempre y casi siempre se da un $24 \%$.

- El 35\% responde nunca y casi nunca al tratarse de: "He escuchado charlas de conservación al medio ambiente".

- En cuanto a la atención a las noticias de tipo ambiental en cualquier medio de comunicación, el 38\% ve o escucha noticias, dándole importancia a las que tienen temática ambiental.

- La siguiente variable hace referencia a la cotidianidad de las conversaciones sobre temas ambientales: $82 \%$ nunca, casi nunca y a veces mantiene pláticas con esta temática. Contrario a la falta de interés por los temas ambientales, un gran porcentaje (68\%) afirma reconocer la importancia de separar la basura.

- El $40 \%$ cree que reciclar es separar basura y $67 \%$ piensa que el gobierno se debe encargar de regular la contaminación ambiental en las empresas. 
- En la afirmación "Considero que en el trabajo se percibe la importancia de los manejos de los desechos contaminantes", el 42\% nunca, casi nunca o a veces lo considera; mientras que el $58 \%$ casi siempre o siempre lo piensa. En el trabajo, el $62 \%$ de los trabajadores nunca, casi nunca y a veces observa que se coloque información preventiva gráfica o textual para promover el buen uso de agua y energía. Durante las jornadas laborales, los trabajadores afirman que siempre (42\%) cuentan con contenedores asignados para los desechos generados, mientras que un $35 \%$ menciona que no se designan contenedores específicos, afirmación que se atribuye a trabajadores con mayor conocimiento de la separación de residuos.

- La misión y visión de la empresa es un aspecto significativo para la identidad de la misma, no obstante, cerca del 50\% de los empleados no se encuentra familiarizados con éstas.

- Ante la pregunta: "¿En qué medida considera que la empresa establece objetivos de mejora ambiental? Por ejemplo, separación de basura, acciones de reducción o reutilización", la mayoría manifiesta que no se observan con regularidad (66\%).

- El $73 \%$ de los trabajadores entre nunca y a veces considera que se realizan estudios sobre los efectos de la descarga de aguas residuales o desechos.

- En las empresas, una fracción afirma que a veces se establecen programas ambientales (23\%); otra, que nunca se establecen (35\%) o casi nunca $(25 \%)$; mientras que los que atestiguan que los programas 
Tecnología y

Ciencias Agua
2020, Instituto Mexicano de Tecnología del Agua

Open Access bajo la licencia CC BY-NC-SA 4.0

(https://creativecommons.org/licenses/by-nc-sa/4.0/)

son frecuentes es el $17 \%$. Pero el $45 \%$ afirma nunca haber participado en programas o actividades de educación ambiental.

En general, los resultados de la encuesta se presentan por dominio en la Figura 5, Figura 6 y Figura 7. Un escaso porcentaje (27\%) tiene un buen nivel de conciencia ambiental. Por su parte, para conocimiento ambiental, $37 \%$ se encuentra entre los niveles malo e insuficiente, y para la percepción de la gestión ambiental un escaso 15\% está entre el nivel bueno y excelente.

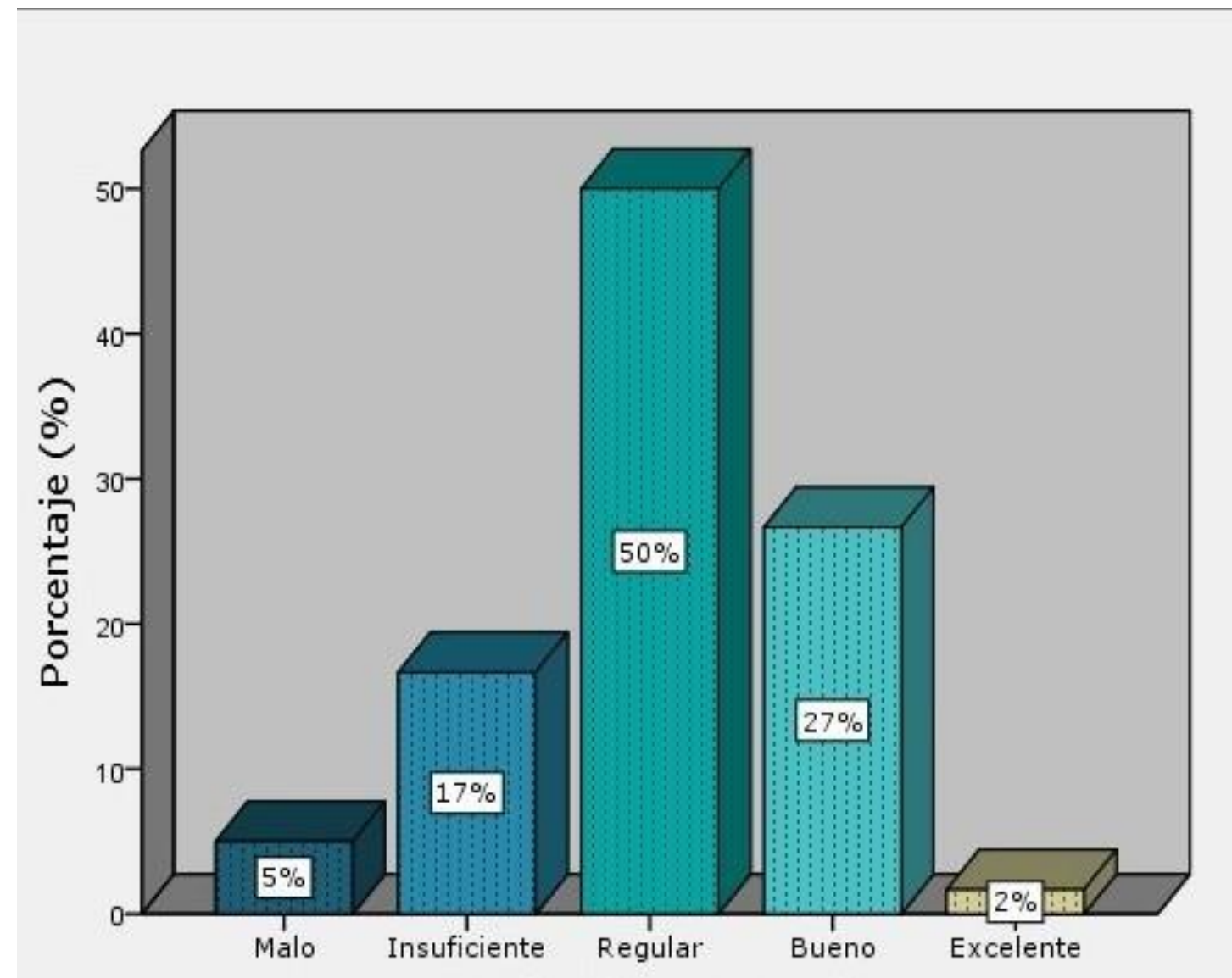


Tecnología y

Ciencias $₫$ Agua
2020, Instituto Mexicano de Tecnología del Agua

Open Access bajo la licencia CC BY-NC-SA 4.0

(https://creativecommons.org/licenses/by-nc-sa/4.0/)

Figura 5. Nivel de conciencia ambiental. Fuente: elaboración propia.

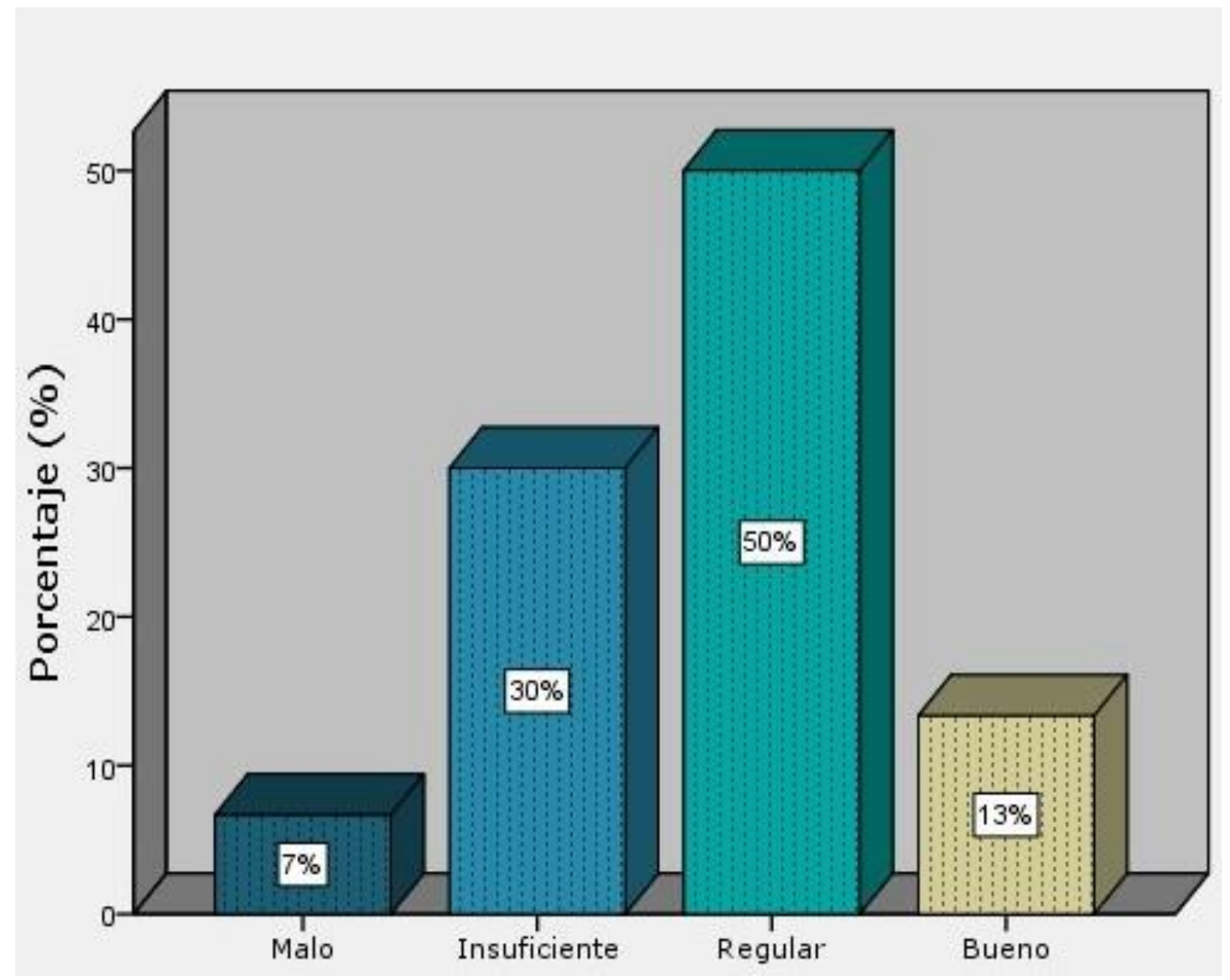

Figura 6. Nivel de conocimiento ambiental. Fuente: elaboración propia. 
Tecnología y

Ciencias $₫$ Agua
2020, Instituto Mexicano de Tecnología del Agua

Open Access bajo la licencia CC BY-NC-SA 4.0

(https://creativecommons.org/licenses/by-nc-sa/4.0/)

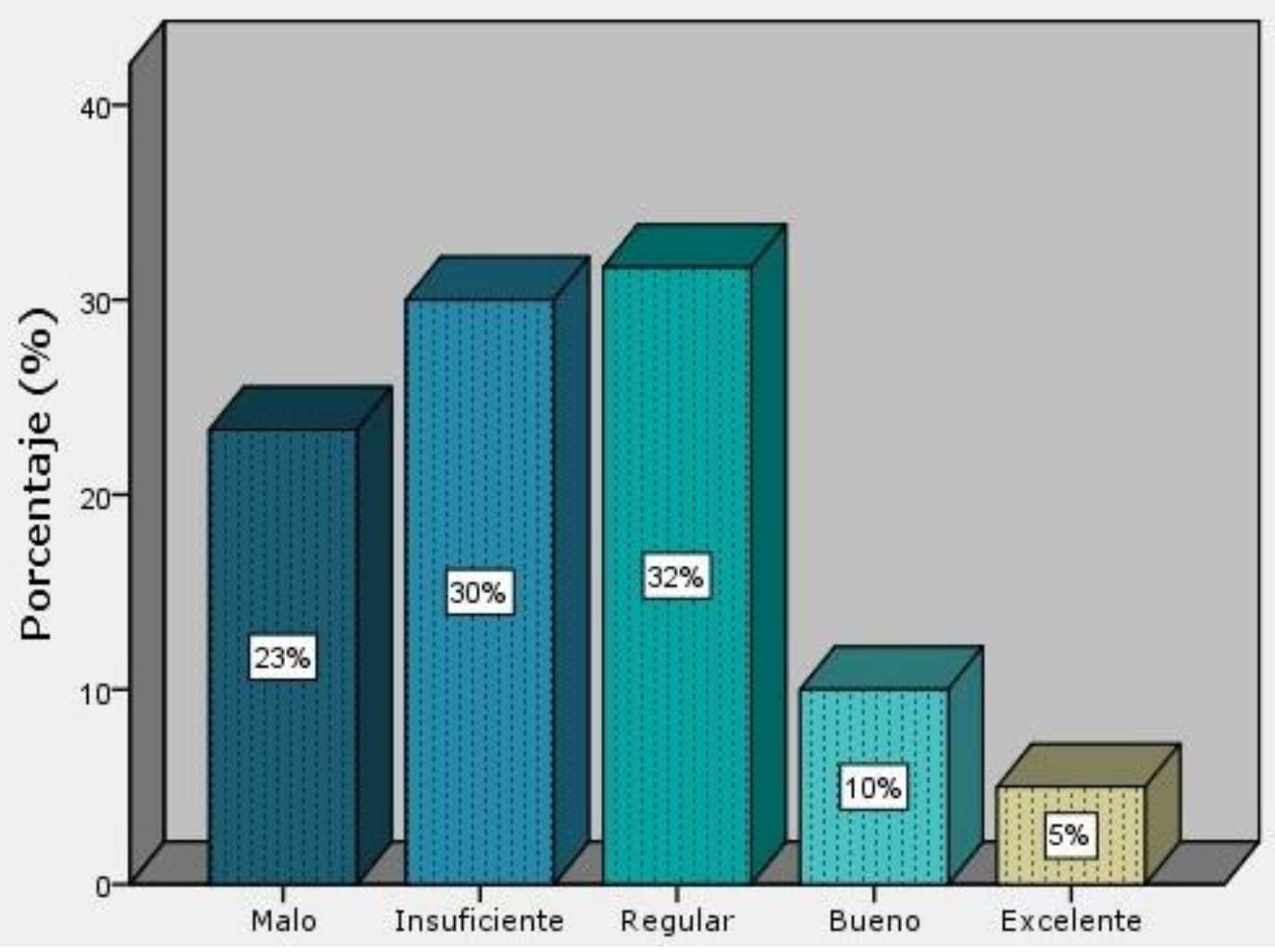

Figura 7. Nivel de percepción de la gestión ambiental. Fuente: elaboración propia.

\section{Resultados descriptivos posteriores al taller de educación ambiental}


Tecnología y

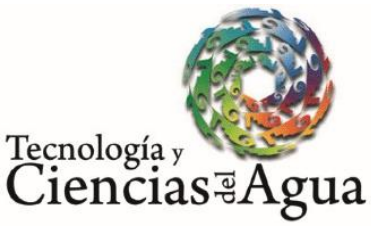

2020, Instituto Mexicano de Tecnología del Agua

Open Access bajo la licencia CCBY-NC-SA 4.0

(https://creativecommons.org/licenses/by-nc-sa/4.0/)

Una vez realizado el taller de educación ambiental, se procedió a evaluar una muestra aleatoria de trabajadores de las empresas. Los resultados más relevantes de la encuesta se presentan a continuación:

- La proporción de la edad de los trabajadores de 18 a 22, de 23 a 27, de 28 a 32 y de 38 o más se encontró entre el 19 y $26 \%$; el rango de edad de 33 a 37 años fue significativamente menor, con un $3 \%$.

- Del total de los trabajadores encuestados, $52 \%$ son mujeres y $48 \%$ hombres. De éstos, el $52 \%$ estaban casados y $48 \%$ solteros.

- El $13 \%$ de los encuestados reportó contar con estudios de licenciatura y laboran como recepcionistas o personal de mantenimiento. El 10\% tiene nivel primaria; 39\%, secundaria; 39\%, preparatoria.

- Las ocupaciones de los trabajadores son recepcionista (16\%); personal de limpieza (3\%); mantenimiento $(6 \%)$; cocinero $(29 \%)$; camarero $(16 \%) ;$ y el resto $(29 \%)$, ayudantes.

- Ante la frase: "Tengo conocimiento de las sustancias y materiales contaminantes que se generan debido a las actividades de mantenimiento, limpieza, cocina o servicio", el 35\% de los sujetos está entre los niveles de nunca, casi nunca y a veces. Este porcentaje representa una diferencia del $14 \%$ con la primera encuesta. También es posible destacar que el nivel de casi siempre y siempre representó el 64\%.

- El $78 \%$ de los trabajadores siempre o casi siempre se esfuerza por ahorrar recursos como energía eléctrica y agua durante sus actividades laborales. Pero en el hogar es mayor el porcentaje que reporta realizaracciones para el cuidado de energía eléctrica y agua, con un $87 \%$. 
- La mayoría comprendió, a partir del taller, el daño ambiental por el empleo de aerosoles, pero el 19\% mencionó que los usará por necesidad.

- Ante la frase, "He escuchado y me interesan charlas de conservación del ambiente", sólo el 9\% respondió nunca y casi nunca, a diferencia del 35\% que respondió nunca y casi nunca antes de tomar el taller.

- Del $67 \%$ inicial entre siempre, casi siempre y a veces deja conectados aparatos electrodomésticos se redujo al 51\%.

- El $80 \%$ siempre percibe basura tirada mientras camina por la ciudad y el $33 \%$ manifestó interés por colaborar en campañas o programas de conservación ambiental.

- Un 45\% respondió a la afirmación nunca, casi nunca y a veces ante: "Uso productos reciclados". Entre los que siempre y casi siempre se da un 55\%.

- El $32 \%$ de los trabajadores se preocupa por separar la basura, incluyendo el hogar; pero $45 \%$ continúa manifestando que nunca, casi nunca o a veces la separa.

- El $74 \%$ comprende que la disposición de la basura es un tema relevante debido a su implicación ambiental.

- En cuanto a la atención a las noticias de tipo ambiental en cualquier medio de comunicación, el $61 \%$ siempre y casi siempre ve o escucha noticias, dándole importancia a las que tienen temática ambiental.

- A la afirmación "Periódicamente mantengo conversaciones sobre temas ambientales", $80 \%$ nunca, casi nunca y a veces mantiene pláticas con esta temática; pero cuando tiene el conocimiento de alguna situación con 
respecto a la contaminación por residuos reconoce la importancia de separar la basura (77\% siempre y casi siempre).

- El 23\% reconoce el tipo de envase o embalaje (plástico, cartón, papel) al comprar productos y lo toma en cuenta en su disposición.

- A la variable sobre "Reciclar es separar basura", el 32\% afirma que nunca y el mismo porcentaje para siempre.

- El $52 \%$ opina que la responsabilidad de regular la contaminación ambiental generada por las empresas es del gobierno.

- De acuerdo con la aseveración "Considero que en el trabajo se percibe la importancia de los manejos de los desechos contaminantes", el 45\% nunca, casi nunca o a veces lo considera, mientras que el $55 \%$ casi siempre o siempre lo considera. De igual forma, el $58 \%$ de los trabajadores nunca, casi nunca y a veces, observa que se coloque información preventiva gráfica o textual para promover el buen uso de agua y energía. También han observado que en el lugar del trabajo (42\%) cuentan con espacios y/o contenedores asignados para los desechos generados; mientras que un $35 \%$ menciona que no se designan contenedores específicos con base en un sistema eficiente de separación de residuos.

- La pregunta "¿En qué medida considera que la empresa establece objetivos de mejora ambiental? Por ejemplo, separación de basura, acciones de reducción o reúso, una fracción significativa", el 52\% no observa mejoras ambientales.

- Cerca del $13 \%$ de los empleados piensa que no se les familiariza con la misión y la visión de la empresa, pero el 50\% manifiesta tener 
Teçnología y

Ciencias $₫$ Agua
2020, Instituto Mexicano de Tecnología del Agua

Open Access bajo la licencia CC BY-NC-SA 4.0

(https://creativecommons.org/licenses/by-nc-sa/4.0/)

conocimiento de éstas, pues han observado que se encuentran en las instalaciones.

- Un $29 \%$ desconoce los programas ambientales de la empresa, pero el mismo porcentaje está al tanto de los programas.

- En las empresas, una fracción asegura que de acuerdo con su percepción de la ley, la empresa siempre cumple con la legislación en materia ambiental $(13 \%)$, otra que nunca $(13 \%)$ y casi nunca $(16 \%)$; mientras que los que atestiguan que los programas son frecuentes son alrededor del $26 \%$, pero el $32 \%$ no está seguro, ya que no les es familiar la información.

Los resultados se observan en la Figura 8, Figura 9 y Figura 10, pues presentan el nivel general por cada dominio posterior a la aplicación del taller de educación ambiental.

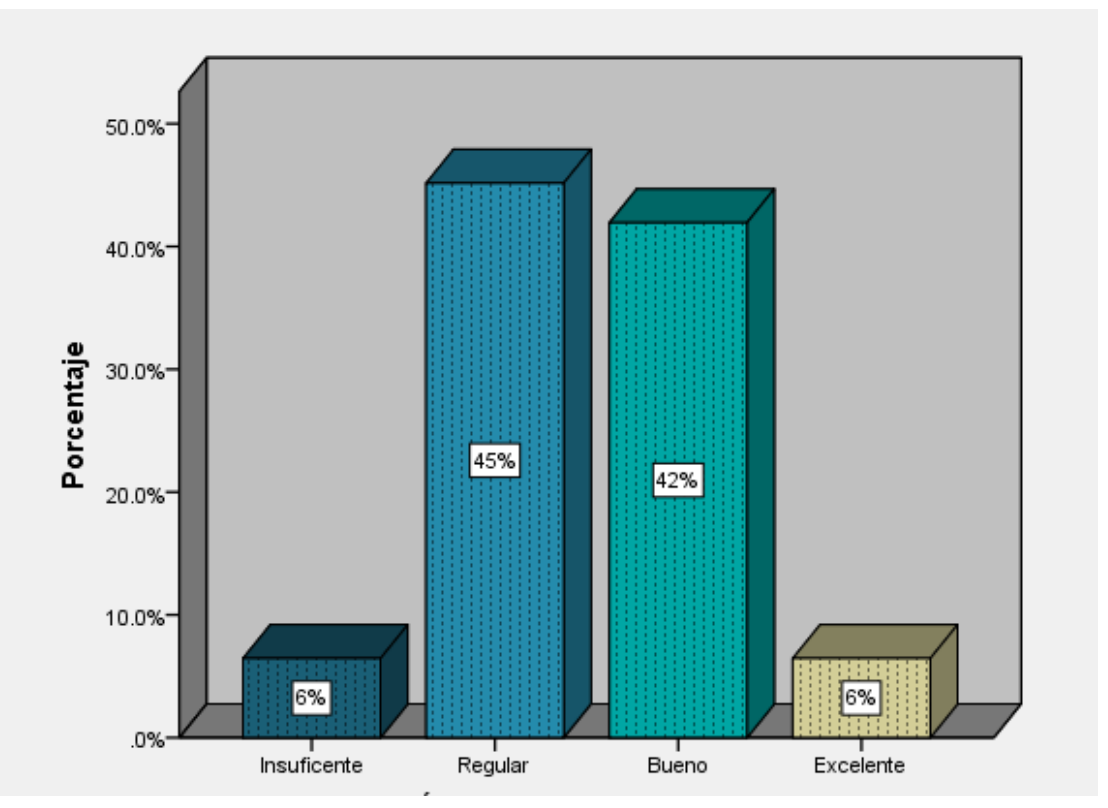


Teçnología y

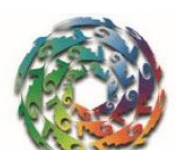

Ciencias $\approx$ Agua
2020, Instituto Mexicano de Tecnología del Agua

Open Access bajo la licencia CC BY-NC-SA 4.0

(https://creativecommons.org/licenses/by-nc-sa/4.0/)

Figura 8. Nivel de conciencia ambiental Fuente: elaboración propia.

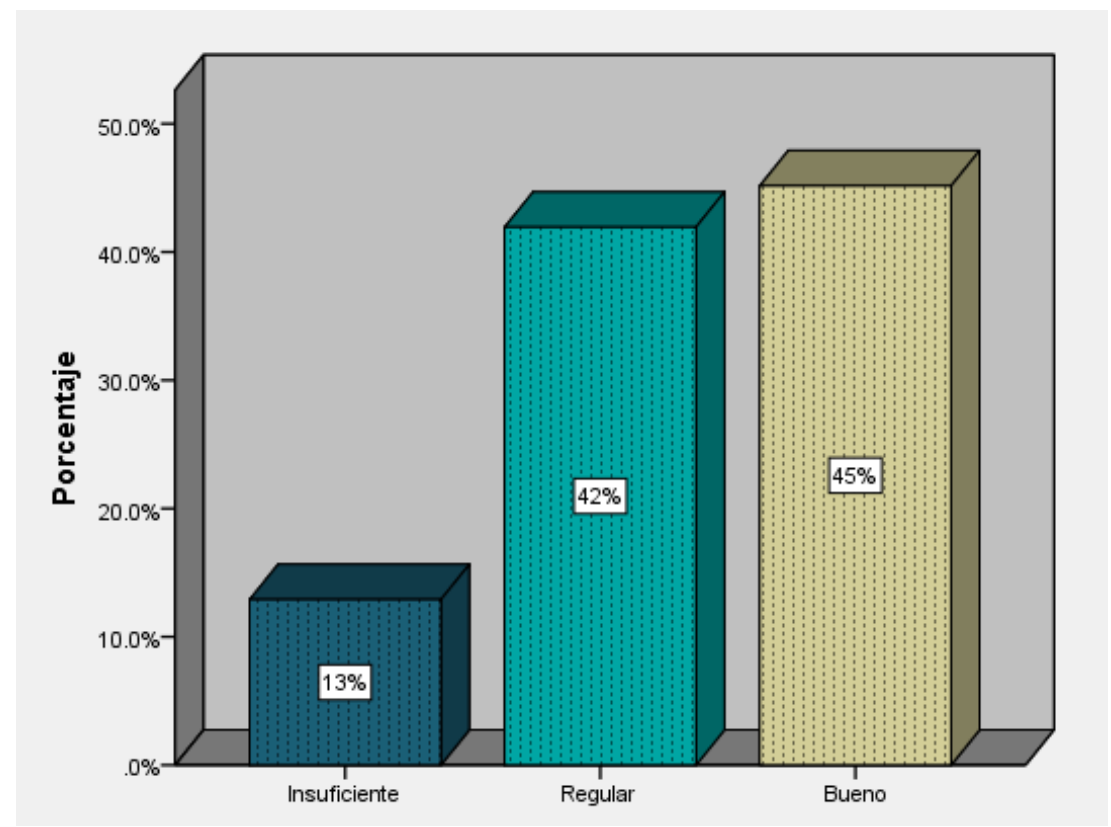

Figura 9. Nivel de conocimiento ambiental. Fuente: elaboración propia. 
Teçnología y

Ciencias $\approx$ Agua
2020, Instituto Mexicano de Tecnología del Agua

Open Access bajo la licencia CC BY-NC-SA 4.0

(https://creativecommons.org/licenses/by-nc-sa/4.0/)

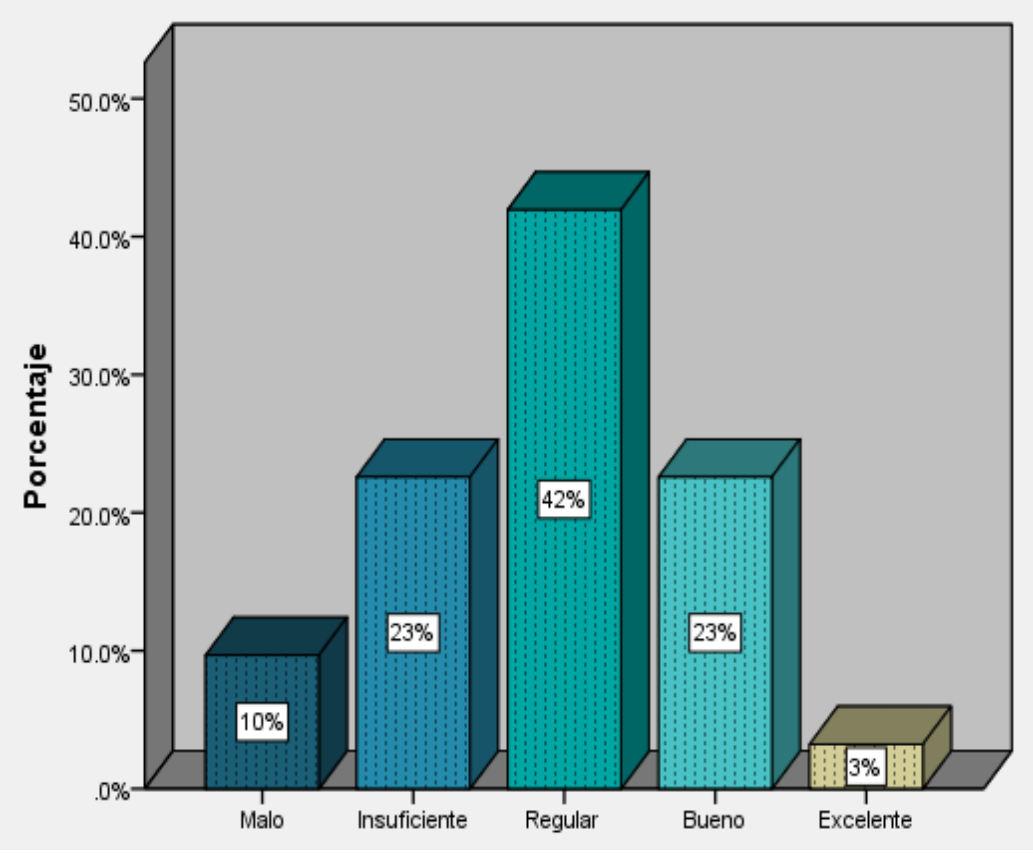

Figura 10. Nivel de percepción de la gestión ambiental. Fuente: elaboración propia.

Después de la actividad experimental, con respecto al nivel de conciencia ambiental, se registraron resultados en cuatro categorías. La categoría Bueno pasó de 27 a 42\%; Excelente, aumentó de 2 a 6\%.

Para conocimiento ambiental, el porcentaje de Bueno aumentó en $33 \%$ y para Gestión un $13 \%$. El nivel de conocimiento también tuvo una tendencia en aumentar en las categorías Bueno y Regular, que tuvieron alrededor de $45 \%$ cada uno. 
La percepción de gestión ambiental adoptó una distribución de campana: la categoría Malo mostró una tendencia a disminuir en la mitad y la de Insuficiente disminuyó $7 \%$.

\section{Análisis de la efectividad del taller de educación ambiental}

Teniendo como instrumento de evaluación la encuesta fue indispensable establecer si existió diferencia en la proporción de respuesta de los dominios. Para esto, se determinó si las opciones de respuesta - por ejemplo, para conocimiento ambiental- presentaban la misma frecuencia en cada una de las clasificaciones (malo, insuficiente, regular, bueno y excelente). Es decir, si las probabilidades de cada una de las clasificaciones mostraban o no diferencias estadísticas. Esto se infirió con un nivel de significación de 0.05 , que para conciencia ambiental tuvo un valor de $X^{2}$ de 45.500, el cual se observa en la Tabla 1; para la probabilidad de $P<0.05$, el valor crítico es 7.815 ; entonces 45.500 se ubica en la zona de rechazo. Ello significa que al menos uno de los porcentajes o proporciones de cada una de las clasificaciones es diferente a los demás. 
Teçnología y

Ciencias $\stackrel{\unlhd}{\unlhd}$ gua
2020, Instituto Mexicano de Tecnología del Agua

Open Access bajo la licencia CC BY-NC-SA 4.0

(https://creativecommons.org/licenses/by-nc-sa/4.0/)

Tabla 1. Estadístico de prueba chi cuadrada.

\begin{tabular}{|l|r|r|r|}
\hline \multicolumn{4}{|c|}{ Estadísticos de prueba } \\
\hline \multicolumn{1}{|c|}{$\boldsymbol{X}^{\mathbf{2}}$} & $\begin{array}{c}\text { Conciencia } \\
\text { ambiental }\end{array}$ & $\begin{array}{c}\text { Gestión } \\
\text { ambiental }\end{array}$ & $\begin{array}{c}\text { Conocimiento } \\
\text { ambiental }\end{array}$ \\
\hline Chi cuadrada & $45.500^{\mathrm{a}}$ & $17.167^{\mathrm{a}}$ & $47.500^{\mathrm{a}}$ \\
\hline $\begin{array}{l}\text { Grados } \\
\text { libertad }\end{array}$ & 4 & 4 & \\
\hline Significancia. \\
asintótica
\end{tabular}

Por lo tanto, las personas encuestadas no están distribuidas de manera uniforme en cada una de las clasificaciones para la conciencia ambiental. Así, para conciencia ambiental, una vez determinado que los porcentajes de las clasificaciones de respuesta son distintos, es posible argumentar que el nivel regular es el que se presenta con mayor influencia en la distribución de los datos.

Para conocimiento ambiental se obtuvo un valor de $X^{2}$ de 17.167, con nivel de significación de 0.05 y cuatro grados de libertad; el valor de la tabla chi cuadrada es 9.488. Al comparar el valor obtenido con el valor 
crítico es posible afirmar que se rechaza la hipótesis nula que establece la igualdad entre las proporciones de las clasificaciones.

Entonces, las respuestas no presentan la misma frecuencia. La clasificación que presenta mayor frecuencia es regular. A partir de esto, se comprende que la diferencia entre la frecuencia de respuesta para las clasificaciones es significativa -por ejemplo, de conocimiento bueno y regular-, por lo que, en general, las empresas presentan un nivel regular.

Para gestión ambiental, el valor crítico también es superado por el calculado. Entonces es posible rechazar la hipótesis de igualdad al 95\%. Las respuestas de los encuestados no se presentan con la misma frecuencia en cada una de las clasificaciones, de tal forma que existen tanto empleados con un nivel bueno de conocimiento en gestión ambiental como los que tienen un nivel malo o insuficiente. De acuerdo con este análisis, el taller propuesto para los trabajadores de las empresas fue de carácter introductorio, pues los resultados del nivel de educación ambiental son, en su mayoría, insuficiente o regular. Además, el nivel de estudios dominante fue secundaria, por lo que se planteó un taller de nivel básico.

Una vez hecha la primera encuesta para determinar el nivel de educación ambiental en los paraderos, se diseñó e impartió el taller. Para el análisis comparativo de los resultados anteriores y posteriores al taller de educación ambiental se aplicó una prueba $t$ student.

En general, las hipótesis para determinar diferencias entre el nivel de educación anterior y posterior al taller son las siguientes: $\mathrm{HO}$, no existe diferencia estadística significativa entre el nivel de educación ambiental 
anterior y posterior al taller; $\mathrm{H} 1$, existe una diferencia significativa entre el nivel de educación ambiental anteriory posterior al taller.

En la Tabla 2 se muestra que el valor resultante de $t$ es 2.47 , de acuerdo con 89 grados de libertad; se observa que en los valores críticos para la distribución, con un alfa de 0.05 , existe un valor de 1.98 . Por lo tanto, al observar que el valor de 2.47 es mayor al valor crítico, se rechaza la hipótesis nula, y se acepta que existe diferencia en el nivel de conciencia ambiental anteriory después del taller.

Tabla 2. Prueba $t$ student para comparar la categoría "conciencia ambiental".

\begin{tabular}{|c|c|c|c|c|c|c|c|}
\hline \multirow{3}{*}{ t student } & \multicolumn{7}{|c|}{ Prueba $t$ para la igualdad de medias } \\
\hline & $t$ & $\begin{array}{c}\text { Grados } \\
\text { de } \\
\text { libertad }\end{array}$ & $\begin{array}{c}\text { Significancia. } \\
\text { (bila-teral) }\end{array}$ & de medias & $\begin{array}{c}\text { Error } \\
\text { típico de } \\
\text { la } \\
\text { diferencia }\end{array}$ & $\begin{array}{r}95 \% \\
\text { interv } \\
\text { confian } \\
\text { la dife }\end{array}$ & $\begin{array}{l}\% \text { de } \\
\text { valo de } \\
\text { Tza para } \\
\text { erencia }\end{array}$ \\
\hline & & & & & & Inferior & Superior \\
\hline Categorías $\begin{array}{l}\begin{array}{l}\text { Se han } \\
\text { asumido }\end{array} \\
\text { varianzas } \\
\text { iguales }\end{array}$ & 2.47 & 89 & .015 & 2.86720 & 1.16050 & $\begin{array}{r}- \\
5.17310\end{array}$ & -.56131 \\
\hline
\end{tabular}


Tecnología y

Ciencias $₫$ Agua
2020, Instituto Mexicano de Tecnología del Agua

Open Access bajo la licencia CC BY-NC-SA 4.0

(https://creativecommons.org/licenses/by-nc-sa/4.0/)

\begin{tabular}{|l|l|l|l|r|r|r|r|}
\hline $\begin{array}{l}\text { No se } \\
\text { han } \\
\text { asumido } \\
\text { varianzas } \\
\text { iguales }\end{array}$ & 2.56 & 67.66 & .012 & 2.86720 & 1.11590 & -.64027 \\
\hline
\end{tabular}

Fuente: elaboración propia.

Para conocimiento ambiental, en la Tabla 3 se puede apreciar el valor obtenido de 4.95, con un alfa de 0.05 a 89 grados de libertad; el valor crítico es de 1.987 . Por lo tanto, se asume una diferencia en la categoría "conocimiento ambiental" antes y después de la implementación del taller.

Tabla 3. Prueba $t$ student para la categoría "conocimiento ambiental".

\begin{tabular}{|c|c|c|c|c|c|c|c|}
\hline \multirow{3}{*}{ t student } & \multicolumn{7}{|c|}{ Prueba $t$ para la igualdad de medias } \\
\hline & \multirow[t]{2}{*}{$\boldsymbol{t}$} & \multirow[t]{2}{*}{\begin{tabular}{|c|} 
Grado \\
de \\
libertad
\end{tabular}} & \multirow[t]{2}{*}{\begin{tabular}{|c|} 
Significancia \\
(bilate-ral)
\end{tabular}} & \multirow[t]{2}{*}{$\begin{array}{l}\text { Diferencia } \\
\text { de medias }\end{array}$} & \multirow{2}{*}{$\begin{array}{c}\text { Error } \\
\text { típico de } \\
\text { la } \\
\text { diferencia }\end{array}$} & \multicolumn{2}{|c|}{$\begin{array}{c}\text { 95\% de intervalo } \\
\text { de confianza para la } \\
\text { diferencia }\end{array}$} \\
\hline & & & & & & Inferior & Superior \\
\hline \begin{tabular}{|l|l} 
Sumas & $\begin{array}{l}\text { Se han } \\
\text { asumido } \\
\text { varianzas } \\
\text { iguales }\end{array}$
\end{tabular} & 4.95 & 89 & .000 & 5.8371 & 1.1789 & 8.179 & 3.494 \\
\hline
\end{tabular}


Tecnología y

Ciencias $\stackrel{\Xi}{\unlhd}$ gua
2020, Instituto Mexicano de Tecnología del Agua

Open Access bajo la licencia CC BY-NC-SA 4.0

(https://creativecommons.org/licenses/by-nc-sa/4.0/)

\begin{tabular}{|l|l|l|l|l|l|l|l|}
\hline $\begin{array}{l}\text { No se han } 5.04 \\
\text { asumido } \\
\text { varianzas } \\
\text { iguales }\end{array}$ & 63.99 & .000 & 5.8371 & 1.1568 & 8.148 & 3.525 \\
\hline
\end{tabular}

Fuente: elaboración propia.

En la Tabla 4, para la categoría "gestión ambiental" se indica el valor de 1.853 , con un alfa de 0.05 a 89 grados de libertad, en comparación con el valor 1.987; se asume que no existe diferencia significativa en el nivel de conocimiento en la categoría "gestión ambiental" antes y después del taller.

Tabla 4. Prueba $t$ student para la categoría "gestión ambiental".

\begin{tabular}{|c|c|c|c|c|c|c|c|}
\hline \multirow{3}{*}{ t student } & \multicolumn{7}{|c|}{ Prueba $T$ para la igualdad de medias } \\
\hline & \multirow[t]{2}{*}{$t$} & \multirow[t]{2}{*}{$\begin{array}{c}\text { Grados } \\
\text { de } \\
\text { libertad }\end{array}$} & \multirow[t]{2}{*}{$\begin{array}{c}\text { Significancia. } \\
\text { (bilate-ral) }\end{array}$} & \multirow[t]{2}{*}{$\begin{array}{l}\text { Diferencia } \\
\text { de medias }\end{array}$} & \multirow[t]{2}{*}{\begin{tabular}{|c|} 
Error \\
típico de \\
la \\
diferencia
\end{tabular}} & \multicolumn{2}{|c|}{$\begin{array}{c}95 \% \text { de } \\
\text { intervalo de } \\
\text { confianza para } \\
\text { la diferencia }\end{array}$} \\
\hline & & & & & & Inferior & Superior \\
\hline \begin{tabular}{|l|l|} 
Sumas & $\begin{array}{l}\text { Se han } \\
\text { asumido } \\
\text { varianzas } \\
\text { iguales }\end{array}$ \\
\end{tabular} & 1.853 & 89 & .067 & 3.59 & 1.942 & 7.459 & .260 \\
\hline
\end{tabular}


Tecnología y

Ciencias $\approx$ Agua
2020, Instituto Mexicano de Tecnología del Agua

Open Access bajo la licencia CC BY-NC-SA 4.0

(https://creativecommons.org/licenses/by-nc-sa/4.0/)

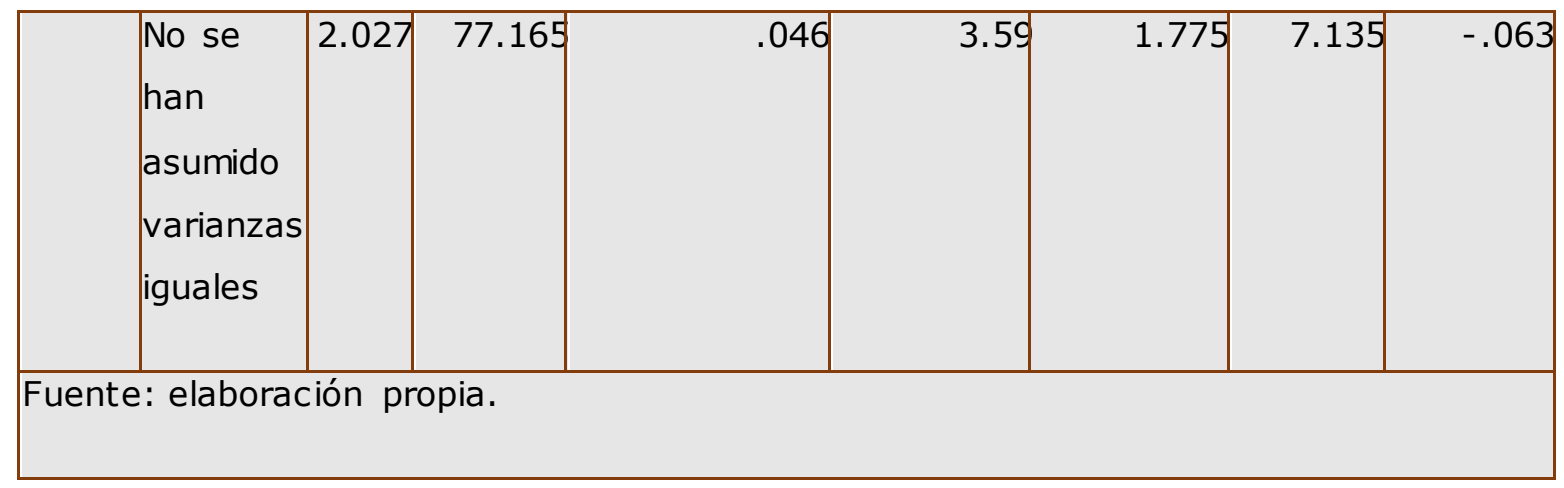

En general, de acuerdo con los resultados comparativos que se muestran en la Figura 11, se puede prestar atención en que el taller de educación ambiental tuvo efecto positivo en los resultados adquiridos, al aplicar por segunda ocasión el nivel de educación ambiental por dominio.

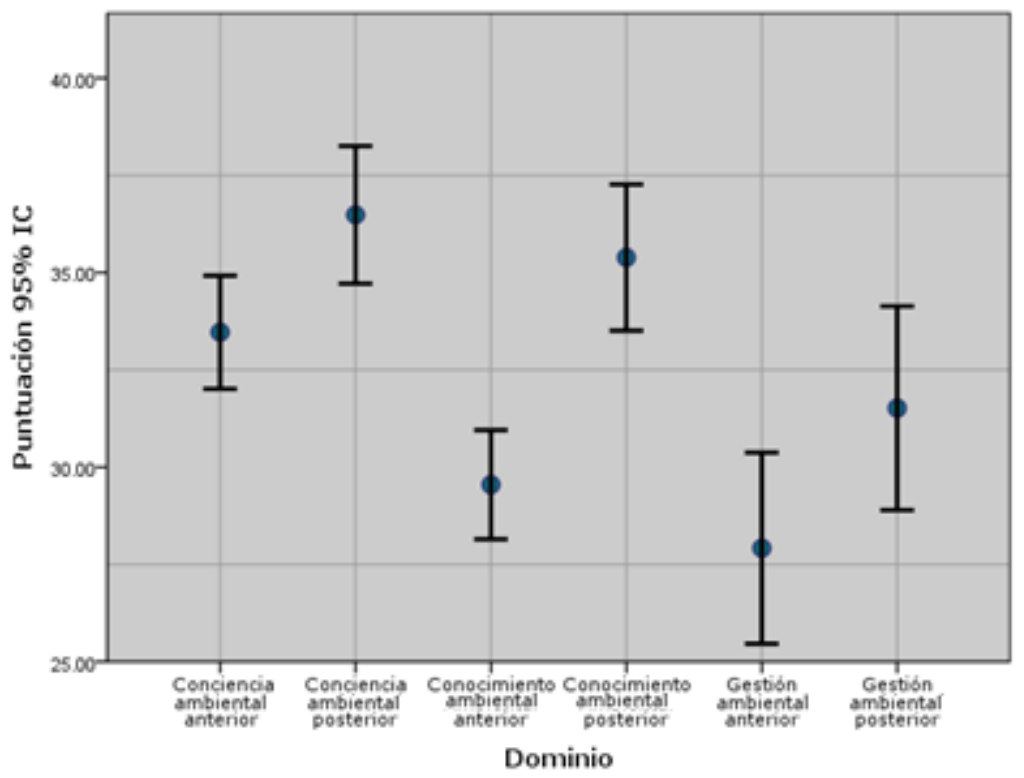

Figura 11. Nivel de educación ambiental promedio antes y después del taller de educación ambiental por dominio. Fuente: elaboración propia. 
Para destacar visiblemente la diferencia en el nivel de educación ambiental, en la Figura 12 se presenta una gráfica comparativa del promedio total obtenido. Como se puede apreciar, existió un impacto positivo: el grupo posterior a la aplicación del taller de educación ambiental tiene una puntuación mucho más alta que el grupo anterior.

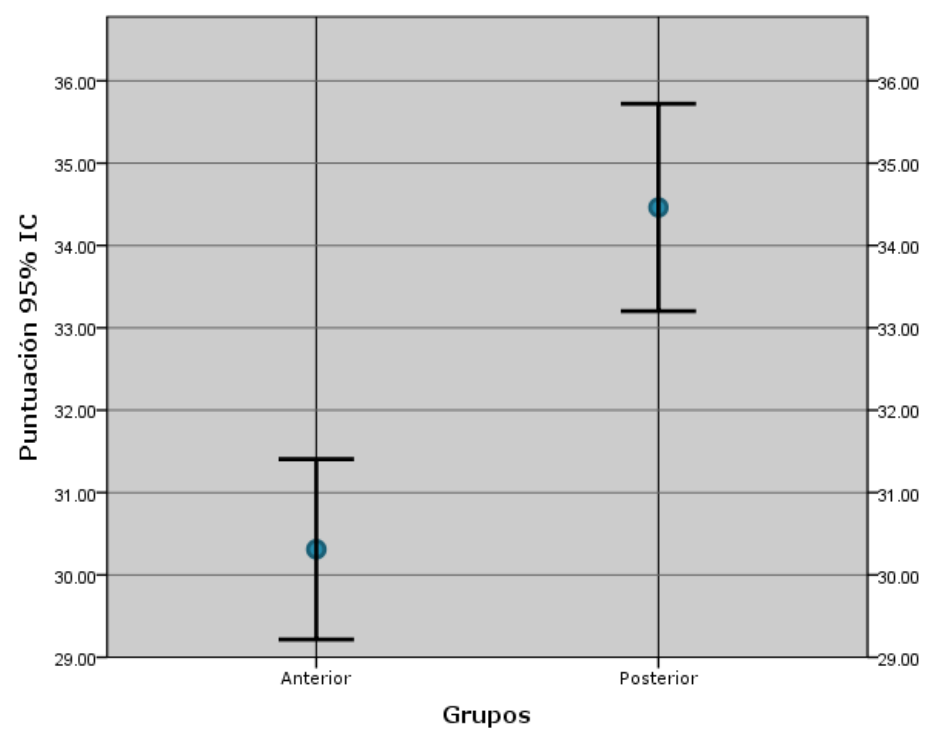

Figura 12. Nivel de educación ambiental promedio anterior y posterior al taller de educación ambiental. Fuente: elaboración propia.

\section{Requisitos legales}


2020, Instituto Mexicano de Tecnología del Agua

Open Access bajo la licencia CC BY-NC-SA 4.0

(https://creativecommons.org/licenses/by-nc-sa/4.0/)

La regulación de la disposición de efluentes por parte de las empresas requiere más atención. Es prioridad dejar claro a las empresas los requisitos que deben cubrir para respetar el marco legal en materia de agua, tal como se presenta en la matriz de requisitos legales (Tabla 5), que en su mayoría no se cumple.

Tabla 5. Requisitos legales en materia de agua.

\begin{tabular}{|c|c|c|c|c|}
\hline $\begin{array}{l}\text { Norma, ley, } \\
\text { reglamento }\end{array}$ & $\begin{array}{l}\text { Rubro o } \\
\text { fracción }\end{array}$ & Descripción & Materia & Cumplimiento \\
\hline $\begin{array}{l}\text { Ley de } \\
\text { Aguas } \\
\text { Nacionales }\end{array}$ & $\begin{array}{l}\text { Título VII, } \\
\text { Capítulo I, } \\
\text { Artículo } 88 \\
\text { Bis II, } \\
\text { Fracción II }\end{array}$ & $\begin{array}{l}\text { Artículo } 88 \text { Bis. Las personas } \\
\text { físicas o morales que efectúen } \\
\text { descargas de aguas residuales a } \\
\text { los cuerpos receptores a que se } \\
\text { refiere la presente Ley deberán: } \\
\text { II. Tratar las aguas residuales } \\
\text { previamente a su vertido a los } \\
\text { cuerpos receptores cuando sea } \\
\text { necesario para cumplir con lo } \\
\text { dispuesto en el permiso de } \\
\text { descarga correspondiente y en las } \\
\text { Normas Oficiales Mexicanas }\end{array}$ & Agua & Sí \\
\hline $\begin{array}{l}\text { Ley de } \\
\text { Aguas } \\
\text { Nacionales }\end{array}$ & $\begin{array}{l}\text { Título VII, } \\
\text { Capítulo I, } \\
\text { Artículo } 88\end{array}$ & $\begin{array}{l}\text { Artículo } 88 \text { Bis. Las personas } \\
\text { físicas o morales que efectúen } \\
\text { descargas de aguas residuales a }\end{array}$ & Agua & No \\
\hline
\end{tabular}


Tecnología y

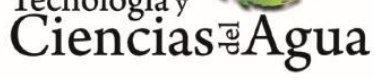

2020, Instituto Mexicano de Tecnología del Agua

Open Access bajo la licencia CC BY-NC-SA 4.0

(https://creativecommons.org/licenses/by-nc-sa/4.0/)

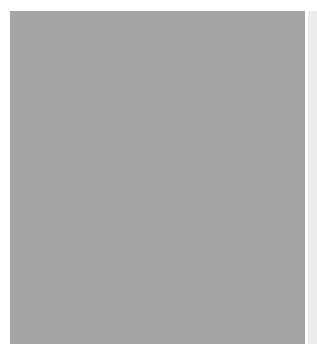

BIS,

los cuerpos receptores a que se

Fracción I

refiere la presente Ley deberán:

I. Contar con el permiso de descarga de aguas residuales mencionado en el Artículo anterior

\section{Ley de}

\section{Aguas}

Nacionales

\section{Ley de}

Aguas

Nacionales

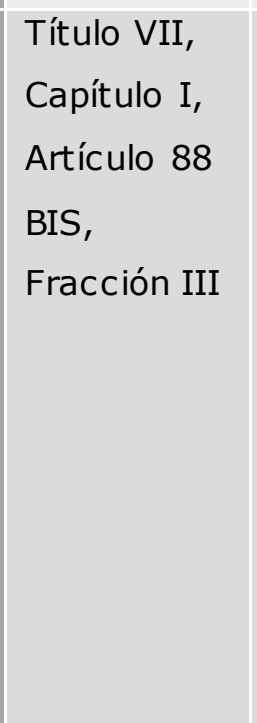

Título VII,

Capítulo I,

Artículo 88

BIS,

Fracción IV
Artículo 88 Bis. Las personas

físicas o morales que efectúen

descargas de aguas residuales a

los cuerpos receptores a que se

refiere la presente Ley deberán:

III. Cubrir, cuando proceda, el derecho federal por el uso o aprovechamiento de bienes de propiedad nacional como cuerpos receptores de las descargas de aguas residuales

\section{Artículo 88 Bis. Las personas}

físicas o morales que efectúen descargas de aguas residuales a los cuerpos receptores a que se refiere la presente Ley deberán: IV. Instalar y mantener en buen estado los aparatos medidores y los accesos para el muestreo necesario en la determinación de las concentraciones de los parámetros previstos en los permisos de descarga
Agua

No

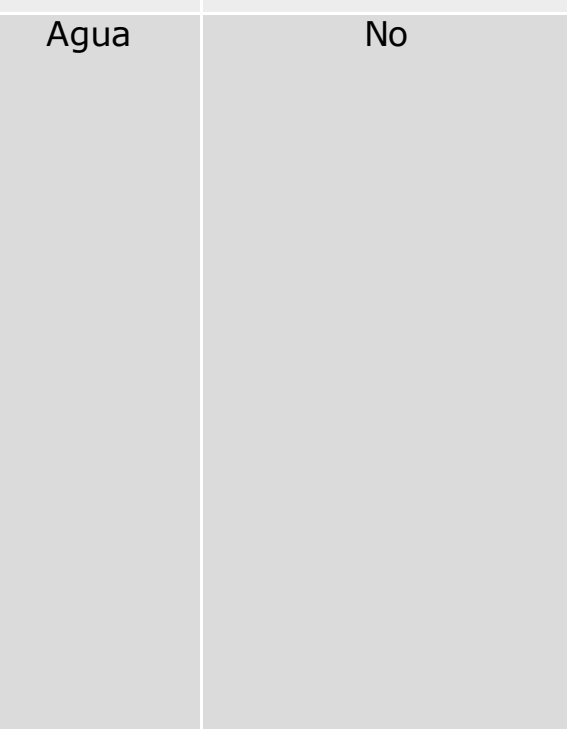


Tecnología y
2020, Instituto Mexicano de Tecnología del Agua

Open Access bajo la licencia CC BY-NC-SA 4.0

(https://creativecommons.org/licenses/by-nc-sa/4.0/)

\begin{tabular}{|c|c|c|c|c|}
\hline $\begin{array}{l}\text { Ley de } \\
\text { Aguas } \\
\text { Nacionales }\end{array}$ & $\begin{array}{l}\text { Título VII, } \\
\text { Capítulo I, } \\
\text { Artículo } 88 \\
\text { BIS, } \\
\text { Fracción V }\end{array}$ & $\begin{array}{l}\text { Artículo } 88 \text { Bis. Las personas } \\
\text { físicas o morales que efectúen } \\
\text { descargas de aguas residuales a } \\
\text { los cuerpos receptores a que se } \\
\text { refiere la presente Ley deberán: } \\
\text { V. Hacer del conocimiento de "la } \\
\text { Autoridad del Agua" los } \\
\text { contaminantes presentes en las } \\
\text { aguas residuales que generen por } \\
\text { causa del proceso industrial o del } \\
\text { servicio que vienen operando, y } \\
\text { que no estuvieran considerados } \\
\text { en las condiciones particulares de } \\
\text { descarga fijadas }\end{array}$ & Agua & No \\
\hline $\begin{array}{l}\text { Ley de } \\
\text { Aguas } \\
\text { Nacionales }\end{array}$ & $\begin{array}{l}\text { Título VII, } \\
\text { Capítulo I, } \\
\text { Artículo } 88 \\
\text { BIS, } \\
\text { Fracción } \\
\text { VIII }\end{array}$ & $\begin{array}{l}\text { Artículo } 88 \text { Bis. Las personas } \\
\text { físicas o morales que efectúen } \\
\text { descargas de aguas residuales a } \\
\text { los cuerpos receptores a que se } \\
\text { refiere la presente Ley deberán: } \\
\text { VIII. Conservar al menos por } \\
\text { cinco años el registro de la } \\
\text { información sobre el monitoreo } \\
\text { que realicen }\end{array}$ & Agua & No \\
\hline $\begin{array}{l}\text { Ley de } \\
\text { Aguas } \\
\text { Nacionales }\end{array}$ & $\begin{array}{l}\text { Título VII, } \\
\text { Capítulo I, } \\
\text { Artículo } 88 \\
\text { BIS, } \\
\text { Fracción } \\
\text { XIb }\end{array}$ & $\begin{array}{l}\text { Artículo } 88 \text { Bis. Las personas } \\
\text { físicas o morales que efectúen } \\
\text { descargas de aguas residuales a } \\
\text { los cuerpos receptores a que se } \\
\text { refiere la presente Ley deberán: } \\
\text { XI. Permitir al personal de "la } \\
\text { Autoridad del Agua" o de "la }\end{array}$ & Agua & Sí \\
\hline
\end{tabular}


Tecnología y

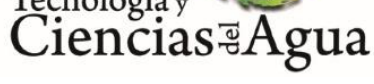

2020, Instituto Mexicano de Tecnología del Agua

Open Access bajo la licencia CC BY-NC-SA 4.0

(https://creativecommons.org/licenses/by-nc-sa/4.0/)

\begin{tabular}{|c|c|c|c|c|}
\hline & & $\begin{array}{l}\text { Procuraduría", conforme a sus } \\
\text { competencias, la realización de: } \\
\text { b. La lectura y verificación del } \\
\text { funcionamiento de los medidores } \\
\text { u otros dispositivos de medición }\end{array}$ & & \\
\hline $\begin{array}{l}\text { Norma } \\
\text { Oficial } \\
\text { Mexicana } \\
\text { "NOM" }\end{array}$ & $\begin{array}{l}\text { NOM-001- } \\
\text { SEMARNAT } \\
-1996\end{array}$ & $\begin{array}{l}\text { NOM-001-SEMARNAT-1996 Que } \\
\text { establece los límites máximos } \\
\text { permisibles de contaminantes en } \\
\text { las descargas de aguas residuales } \\
\text { en aguas y bienes nacionales, } \\
\text { publicada en el Diario Oficial de la } \\
\text { Federación el } 06 \text { de enero de } \\
1997\end{array}$ & Agua & No \\
\hline $\begin{array}{l}\text { Norma } \\
\text { Oficial } \\
\text { Mexicana } \\
\text { "NOM" }\end{array}$ & $\begin{array}{l}\text { NOM-002- } \\
\text { SEMARNAT } \\
-1996\end{array}$ & $\begin{array}{l}\text { NOM-002-SEMARNAT-1996 Que } \\
\text { establece los límites máximos } \\
\text { permisibles de contaminantes en } \\
\text { las descargas de aguas residuales } \\
\text { a los sistemas de alcantarillado } \\
\text { urbano o municipal, publicada en } \\
\text { el Diario Oficial de la Federación } \\
\text { el } 03 \text { de junio de } 1998\end{array}$ & Agua & No \\
\hline $\begin{array}{l}\text { Norma } \\
\text { Oficial } \\
\text { Mexicana } \\
\text { "NOM" }\end{array}$ & $\begin{array}{l}\text { Norma } \\
\text { Mexicana } \\
\text { NMX-AA- } \\
42-1987\end{array}$ & $\begin{array}{l}\text { Norma Mexicana NMX-AA-42- } \\
\text { 1987-calidad del agua- } \\
\text { determinación del número más } \\
\text { probable (NMP) de coliformes } \\
\text { totales, coliformes fecales (termo } \\
\text { tolerantes) y Escherichia coli } \\
\text { presuntiva }\end{array}$ & Agua & No \\
\hline
\end{tabular}




\begin{tabular}{|c|c|c|c|c|}
\hline $\begin{array}{l}\text { Reglamento } \\
\text { de la Ley de } \\
\text { Protección al } \\
\text { Ambiente del } \\
\text { Estado de } \\
\text { Yucatán }\end{array}$ & $\begin{array}{l}\text { Título } \\
\text { Sexto, } \\
\text { Capítulo I, } \\
\text { Artículo } \\
196\end{array}$ & $\begin{array}{l}\text { Artículo } 196 \text {. Las aguas residuales } \\
\text { domésticas tratadas mediante } \\
\text { fosas sépticas deberán ser } \\
\text { vertidas a campos de absorción o } \\
\text { irrigación, cuya profundidad esté } \\
\text { entre tres y cuatro metros sobre } \\
\text { el manto freático del lugar. } \\
\text { Cuando esto no sea posible, las } \\
\text { aguas deberán ser sometidas a } \\
\text { algún otro método de tratamiento } \\
\text { con eficiencia similar a los } \\
\text { sistemas descritos }\end{array}$ & Agua & No \\
\hline $\begin{array}{l}\text { Reglamento } \\
\text { de la Ley de } \\
\text { Protección al } \\
\text { Ambiente del } \\
\text { Estado de } \\
\text { Yucatán }\end{array}$ & $\begin{array}{l}\text { Título VI, } \\
\text { Capítulo I, } \\
\text { Artículo } \\
200\end{array}$ & $\begin{array}{l}\text { Artículo } 200 . \text { La capacidad de } \\
\text { trabajo de las fosas sépticas } \\
\text { deberá determinarse de acuerdo } \\
\text { con el número de usuarios }\end{array}$ & Agua & No \\
\hline
\end{tabular}

\section{Discusión}


Tecnología y

Ciencias $\stackrel{\Xi}{\Im}$ Aua
2020, Instituto Mexicano de Tecnología del Agua

Open Access bajo la licencia CC BY-NC-SA 4.0

(https://creativecommons.org/licenses/by-nc-sa/4.0/)

El turismo es un factor importante del desarrollo de las economías de diversas naciones. Sin embargo, es posible preguntar, ¿ es el turismo una bendición o una maldición?, ¿un trato justo o un truco engañoso?, ¿es el turismo una respuesta al problema del desarrollo de las economías planificadas, o su buena planificación y organización económica hacen del turismo un beneficio solamente empresarial? (Apostolopoulos, 1995). En diversos aspectos del desarrollo de las ciudades, la expansión del turismo tiene aspectos positivos y negativos en lo social, económico y ambiental. En específico, los impactos ambientales son considerados como efectos inversamente proporcionales al desarrollo del turismo, pues mientras más impactos ambientales afectan a una zona turística, menor probabilidad de concurrencia y, en consecuencia, menores ingresos. En este punto no se pretendió abordar la temática de acuerdo con un enfoque en específico, tal como la defensa o la adaptación al turismo; pero la situación actual de éste, en materia ambiental, debe ser caracterizada, con el propósito de presentar herramientas que le permitan cubrir los requisitos legales en materia ambiental. En perspectiva, esto ayuda a mitigar impactos y formular empresas turísticas con conciencia ambiental. Las tendencias de investigación turística se enfocan en su mayoría a aspectos como ecoturismo, turismo rural, masificación del ecoturismo, impactos, gastronomía y desarrollo sostenible, entre otros (Castillo \& Lozano, 2006). No obstante, hablar de turismo sostenible también dirige a aspectos como la educación ambiental ; así, ésta se refiere a la necesidad de informar a las personas acerca de las características del medio en el que actúan y el efecto que dichas acciones tienen sobre el ambiente (Sarukan, 2016). La Organización de las Naciones Unidas para la 
Educación Ambiental se orienta a la sustentabilidad. En México, la Secretaría del Medio Ambiente y Recursos Naturales (Semarnat) ofrece distintas estrategias para fortalecer la educación ambiental y apoyar la legislación por medio de la Ley General del Equilibrio Ecológico y Protección al Ambiente (LEEGEPA) (Akerberg \& Gonzalez, 2016). Entonces, es responsabilidad de los ciudadanos y las empresas conocer los aspectos relacionados con la legislación ambiental. El objetivo de la educación ambiental es prevenir el daño ambiental y en este proyecto específico se aborda el aprovechamiento de zonas turísticas con cenotes como atractivo.

Así, lo que se ha observado es que el aprovechamiento de las zonas turísticas casi siempre es a través de concesiones. En el caso de Valladolid, el flujo turístico se da en algunos hoteles, paraderos turísticos, restaurantes y escasos comercios. De esta forma, Valladolid, a pesar de contar con una riqueza arquitectónica, que combina elementos tradicionales, autóctonos, coloniales populares y espacios de valor ambiental, se convierte en un punto de paso (Sefotur \& UADY, 2013) Sin embargo, las características incipientes del desarrollo turístico y el número limitado de empresas formales ( $\sin$ tomar en cuenta a las cooperativas que administran gran cantidad de cenotes) permiten trabajar con programas enfocados a mitigar la contaminación ambiental de acuerdo con las particularidades, por ejemplo de un hotel.

Por otra parte, resultó interesante observar que las personas que administran un paradero turístico perciben contaminación y vulnerabilidad del acuífero de distintas formas. Así, las percepciones, actitudes, expectativas y comportamientos ante las circunstancias ambientales 
darán forma a diferentes usos y manejo (Moser, Navarro, Ratiu \& Weiss, 2010). Debido a esto, el estudio se enfocó en el diagnóstico del manejo y consumo del recurso hídrico, para después realizar una actividad para concientizar.

Las empresas turísticas tienden a facilitar cursos de educación ambiental sólo para sus empleados, dejando de lado a los huéspedes, lo cual se puede constatar en algunos estudios, como en Irán, donde se ha medido el desempeño ambiental de los hoteles y se ha encontrado que un $80 \%$ de capacita a sus empleados en cuanto a crear conciencia ambiental, pero sólo 43\% lo hace con sus clientes (Aminian, 2012). Con base en ello, se presentó como propuesta generar recursos visuales para dar a conocer tanto a trabajadores como visitantes las políticas ambientales de las empresas.

Durante la actividad de concienciación fue innegable percibir los beneficios económicos que genera el turismo para el ámbito laboral. Sin embargo, también se observó que tal actividad ocasiona gran incremento en la demanda de agua, y en zonas con suelos de carácter permeable es predecible la contaminación de los mantos freáticos, pues por lo general no se realizan actividades especializadas de tratamiento, ya que las aguas se mandan a sumideros. Debido a esto, la principal preocupación son las aguas residuales. Este problema es evidente. Por ejemplo, Nava (2015) realizó un estudio en el cual se caracterizó el grado de contaminación en los cenotes Calavera, Sacbé y Eden, ubicados en Yucatán, y observó contaminación por fosfatos y materia orgánica; los niveles de coliformes fecales rebasaban los límites permitidos por la NOM-245-SSA1-2010, que establece los requisitos sanitarios y niveles máximos de contaminantes 
Tecnología y

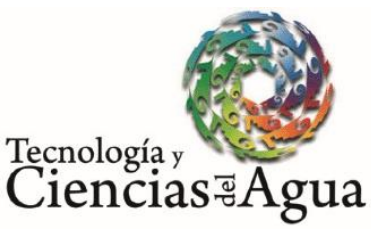

2020, Instituto Mexicano de Tecnología del Agua

Open Access bajo la licencia CC BY-NC-SA 4.0

(https://creativecommons.org/licenses/by-nc-sa/4.0/)

en las albercas (Segob, 2010). Esto ocurre porque las empresas hoteleras o paraderos turísticos no cuentan con sistemas de tratamiento, y si los tienen son defectuosos o no pueden cubrir el tratamiento de los volúmenes de aguas residuales generados, sobre todo en temporada alta. Durante la aplicación de las listas de verificación se observó que una empresa contaba con fosa séptica y otra más con un tanque de almacenamiento, la última mandaba sus aguas residuales a un basurero para evitar rebose. Por tanto, es indispensable que las empresas instalen sistemas de tratamiento eficientes para evitar la infiltración de aguas residuales al manto freático.

La fosa séptica es un recipiente hermético, diseñado y construido para recibir las aguas de desecho; separar los sólidos de los líquidos; suministrar una digestión limitada a la materia orgánica retenida; almacenar los sólidos, y permitir que el líquido clarificado sea descargado para su tratamiento y disposición posterior (Collado, 1992). El agua que sale de la fosa séptica contiene entre 60 y $70 \%$ menos de materia orgánica de la que entró y todavía requiere tratamiento (Quintal, 1992). Este mecanismo de tratamiento se recomendó para el paradero turístico que contaba con poca afluencia turística debido al sector al que se dirigía. La empresa que ofrece servicio de restaurante, visita al cenote y venta de souvenirs, de acuerdo con la observación en campo, recibe al menos 100 visitantes por día. De tal manera que para esta última, en primer lugar se recomendó la remodelación del tanque de almacenamiento, segmentando en etapas para sedimentación, para después instalar una pequeña planta aerobia; aun cuando la fosa séptica para esta cantidad de usuarios se encuentra al límite de aplicación. 
Tecnología y

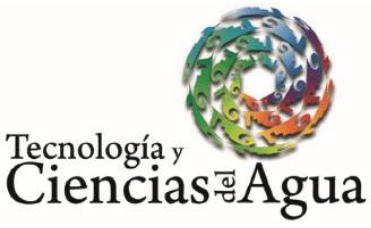

2020, Instituto Mexicano de Tecnología del Agua

Open Access bajo la licencia CCBY-NC-SA 4.0

(https://creativecommons.org/licenses/by-nc-sa/4.0/)

La "Norma Oficial Mexicana NOM-006-CNA-1997 Fosas sépticas prefabricadas, especificaciones y métodos de prueba" ofrece información relevante en cuanto a los métodos y capacidad de trabajo en función del número de usuarios (Segob \& Conagua, 1999). En cuanto a los paraderos que ofrecen hospedaje, generan grandes volúmenes de descarga, para los cuales los tiempos de retención en los tanques para su tratamiento no permitirían la degradación de la materia orgánica y tampoco es posible establecer mayores dimensiones para una fosa que funciona con un sistema mecánico. Por lo tanto, es necesario instalarpequeñas plantas de tratamiento biológico. De acuerdo con los volúmenes emitidos, se recomendó un tratamiento biológico aerobio con aireación extendida. Existen autores que afirman que las fosas sépticas no deberían ser un sistema de elección para la disposición de efluentes en Yucatán (Nava, 2015) debido a la alta permeabilidad del suelo. Sin embargo, el mantenimiento y la adición de un sistema de oxidación permiten la eliminación de agentes microbiológicos.

En cuanto a los aspectos ambientales, la Comisión Nacional del Agua (Conagua) ha expedido normas que regulan la contaminación del agua que proviene de todas las ramas industriales, que han servido para establecer algunas especificaciones y límites permisibles sobre contaminantes en México. Por ejemplo, la NOM-001-SEMARNAT-1996 (Segob, 1996) establece los límites máximos permisibles de contaminantes en las descargas de aguas residuales en aguas y bienes nacionales; no obstante, sólo una empresa demostró realizar estudios de los parámetros de los efluentes, como sólidos, pH y demanda química. La regulación de la disposición de efluentes por parte de las empresas 
requiere más atención del gobierno. La NOM-127- SSA1-1994 (Segob \& Salud, 2019) establece los límites permisibles de calidad y los tratamientos de potabilización del agua para uso y consumo humano que deben cumplir los sistemas de abastecimiento públicos y privados, o cualquier persona física o moral que la distribuya en México. El tratamiento de potabilización para asegurar la calidad abastecida a la población es fundamental, como también lo es la disposición adecuada de las aguas residuales, pues actualmente el agua de abastecimiento en Yucatán es potabilizada con un único método químico: la cloración.

El tratamiento terciario del agua por cloración presenta limitantes, aunque con este método elimina agentes patógenos que podrían provocar enfermedades. Entonces, tomando en consideración que los efluentes no reciben tratamiento adecuado y se infiltran al manto freático, que al mismo tiempo alberga volúmenes de abastecimiento cada vez más contaminados con productos químicos, fármacos y residuales, fue prioridad -con los alcances y limitaciones de este proyecto- dejar claro a las empresas los requisitos que deben cubrir para respetar el marco legal en materia de agua.

Para hacer más eficiente el consumo de agua, se recomendó el uso de tecnología ahorradora; todo tipo de anuncios o recursos que motiven a la reducción del consumo; campañas de concientización para los trabajadores; establecer políticas de la empresa con respecto al cuidado del recurso; y realizar modificaciones a las instalaciones para la reutilización, por ejemplo, en lugar de desechar el agua de las piscinas, una vez agotados los meses de uso, colocar un sistema de bombeo a los tanques de almacenamiento que los lleven a los inodoros. 
Así, durante el diagnóstico, una empresa sustituyó los tanques de los inodoros para reducir el consumo de 9 a 6 litros por descarga. Éstas fueron algunas de las prácticas implementadas durante el taller de educación ambiental, posterior al cual se determinó, por medio de la encuesta, que para la categoría de bueno en conciencia, conocimiento y percepción de la gestión se tuvo un aumento de 15, 33 y 13\%, respectivamente.

La proporcionalidad de incremento en las categorías de excelente y bueno podría indicar que el nivel de conciencia y conocimiento ambiental después del tallerse vio influenciado por el nuevo conocimiento adquirido.

Aunque se reconocen las limitantes de una encuesta para medir la conciencia ambiental - ya que es una variable muy subjetiva y se asume que los resultados sólo representan a las empresas evaluadas-, también se contempla la utilidad de los talleres de educación ambiental para mejorar la sensibilización.

Es muy probable que los trabajadores, al estar enfocados en estos temas ambientales, ahora reconozcan los problemas locales. Por ejemplo, en un estudio sobre el comportamiento y la conciencia ambiental en empresas turísticas, Ilevados a cabo en Oriente, se han detectado cambios positivos en las pequeñas empresas, influenciados por las nuevas políticas de desarrollo turístico, en aspectos de ahorro de energía, conservación de agua, gestión responsable de los residuos, y mejoras en las prácticas y capacitación (Min, 2011).

Como primer paso, se debe considerar que para hacer las soluciones más atractivas a los hoteleros, se recomienda presentarlas como una 
inversión, acompañadas de los beneficios que otorga proporcionar educación ambiental y el consecuente aumento de la conciencia en esta materia; se demuestra el ahorro de costos y recursos; y se tiene acceso al prestigio que proporcionan las certificaciones ambientales y estándares internacionales de gestión ambiental; cumplir con la legislación ambiental, e incentivar en los turistas la demanda de prácticas verdes o el uso de eco-innovaciones de procesos de producción y reducción de residuos, para realizar un cambio significativo en su comportamiento. Para todo ello es necesario conocer al sector turístico atendido y efectuar estudios complementarios, a fin de adaptar y aplicar otras metodologías para evaluar la sustentabilidad en la industria turística, justamente como los análisis FODA.

Por lo tanto, es muy probable que los talleres de educación ambiental permitan la sensibilización de los trabajadores sobre los efectos del turismo, su huella ecológica y el papel que desempeñan al aplicar buenas prácticas para mitigar el impacto ambiental.

\section{Conclusiones}


Esta investigación logró diagnosticar la gestión del recurso hídrico en empresas con carácter turístico, pues se generaron las listas de no conformidades a partir de los instrumentos y las matrices de requisitos legales para las empresas turísticas participantes en materia de agua y agua residual.

Durante gran parte del periodo de ejecución del proyecto se tuvo contacto con el personal que labora en la empresa y se platicó con los representantes para establecer la vinculación y poder llevar a cabalidad el estudio.

A pesar de que son múltiples los requisitos que deben cubrir las empresas para cubrir los aspectos relacionados con la legislación en materia de agua, es posible afirmar que no se tenía cabal conocimiento de ellas, como cuál era la solicitud de permiso para descarga de aguas residuales. Sin embargo, la empresa se manifestó comprometida en realizar a corto y mediano plazos, las medidas necesarias para no presentar en un futuro las no conformidades.

El conocimiento de los volúmenes de aguas y costos relacionados de acuerdo con sus actividades permitirá establecer las actividades para las cuales se puede ahorrar o modificar con sistemas de tecnología verde, por ejemplo, en los grifos, y con respecto al tratamiento de aguas. En última instancia se recomiendan fosas sépticas, aunado a un tratamiento oxidativo. Para el cenote Zaci, con mayor afluencia turística, se recomienda un sistema de tratamiento biológico en una pequeña planta de lodos activos. 
Todos los empleados estuvieron comprometidos en la conservación y el cuidado del recurso hídrico por medio de la regulación de actividades, adoptando una actitud positiva. Por lo tanto, es viable cubrir los trámites o requisitos que establecen las secretarías y que se presentaron en este proyecto.

Durante el estudio se determinó que se tiene conocimiento limitado sobre actividades implicadas en el cuidado del medio ambiente, por lo que se planteó una actividad de educación ambiental, la cual se ejecutó con éxito.

De los resultados obtenidos en las encuestas y talleres es posible afirmar que existe una proporción equitativa entre hombres y mujeres contratados en la empresa.

El nivel educativo preponderante es secundario y el estado civil presenta frecuencia igualitaria para los casados y solteros.

La conciencia y el conocimiento ambiental no presentan una distribución equitativa de acuerdo con el número de personas en las distintas clasificaciones (con base en la primera encuesta); la mayoría se encontró en el nivel insuficiente o regular. Por tanto, los talleres proyectados incluyeron aspectos básicos relacionados con las características siguientes: puesto de los trabajadores; injerencia de los trabajadores en aspectos ambientales; nivel obtenido que arrojó un taller de educación ambiental básico; desarrollo de un taller de capacitación con aspectos prácticos. 
Al participar en el taller, los trabajadores mejoraron de forma significativa su puntuación en las encuestas y demostraron mayor interés en los aspectos ambientales planteados durante las actividades.

\section{Agradecimientos}

Se agradece al Instituto Tecnológico Superior de Valladolid por el apoyo administrativo para los procedimientos de vinculación.

\section{Referencias}

Ávila-Akerberg, Víctor, \& González-Martínez, Tanya (2016). Participación social y educación ambiental para la conservación. Un estudio de caso con niños y jóvenes de una zona rural periurbana. Teoría y Praxis, (19), 119-136. Recuperado de https://www.redalyc.org/articulo.oa?id=4561/456146535007

Aminian, A. (2012). Environmental performance measurement of tourism accommodations in the pilgrimage urban areas: The case of the Holy City of Mashhad, Iran. Procedia Social and Behavioral Sciences, $35,514-522$.

Apostolopoulos, Y. (1995). Transnational tourism and socioeconomic development issues, implications, and alternatives. Miami, USA: Miami University. 
Tecnología y

Ciencias Agua
2020, Instituto Mexicano de Tecnología del Agua

Open Access bajo la licencia CC BY-NC-SA 4.0

(https://creativecommons.org/licenses/by-nc-sa/4.0/)

Castillo, N. M., \& Lozano, C. M. (2006). Apuntes para investigación turística. Chetumal, México: Alfa/Zeta.

Celina, H., \& Campo, A. (2005). Aproximación al uso del coeficiente alfa de Cronbach. Revista Colombiana de Psiquiatría, 34(004), 572-580. Recuperado de http://redalyc.uaemex.mx/pdf/806/80634409.pdf

Collado, L. R. (1992). Depuración de aguas residuales en pequeñas comunidades. Madrid, España: Colegio de Ingenieros de Caminos, Canales y Puertos.

Min, W. (2011). An analysis on environmental awareness and behavior in Chinese hospitality industry-a case of Xiamen City. Energy Procedia, $5,1126-1137$.

Moser, G., Navarro, O., Ratiu, E. \& Weiss, K. (2010). Cultural background and environmental context of water. In: Corral-Verdugo, V., GarciaCadena. C., \& Frias-Armenta, M. (eds.). Psychological approaches to sustainability: Current trends in theory, research and applications (pp. 337-360). New York, USA: Nova Science Publishers, Inc.

Nava, G. V. (2015). Percepción, conocimiento local y descripción de la calidad de agua de cenotes de interés turístico y recreacional. Mérida, México: Centro de Investigación de Estudios Avanzados, Instituto Politécnico Nacional.

Palos, D. H. (2005). La educación ambiental como proceso de cambio en la cultura laboral de las pequeñas y medianas empresas (tesis de maestría). Universidad de Guadalajara, Zapopan, Jalisco. Recuperado

de 
http://biblioteca.cucba.udg.mx:8080/xmlui/bitstream/handle/123 456789/5354/Palos_Delgadillo_Humberto.pdf?sequence $=1$

Palos, D. H. (2010). La educación ambiental en las pequeñas y medianas empresas: propuesta de un modelo educativo medioambiental. Zapopan, México: Universidad de Guadalajara.

Quintal, F. C. A. (1992). Propuesta para el diseño, construcción y mantenimiento de sistemas de tanques sépticos de Yucatán. Revista de la Facultad de Ingeniería, Universidad Autónoma de Yucatán, 21, $35-44$.

Sarukan , J. (2016). Prefacio. En: Barahona, A., \& Almeida-Leñero, L.(coords.). Educación para la conservación. Ciudad de México, México: Universidad Nacional Autonoma de México-Facultad de Ciencias-Coordinación de Servicios Editoriales.

Segob, Secretaría de Gobernación. (1996). NOM-001-SEMARNAT-1996. Que establece los límites maximos permisibles de contaminantes en las descargas de aguas residuales en aguas y bienes nacionales. Recuperado de https://www.gob.mx/cms/uploads/attachment/file/105139/Norma s_Oficiales_Mexicanas.pdf

Segob, Secretaría de Gobernación. (2010). NOM-245-SSA1-2010, Que establece los requisitos sanitarios y niveles máximos de contaminantes en las albercas. Recuperado de http://dof.gob.mx/nota_detalle.php?codigo $=5256066 \&$ fecha $=25 / 0$ $6 / 2012$ 
Segob \& Conagua, Secretaría de Gobernación \& Comisión Nacional del Agua. (1999). NOM-006-CNA-1997. Recuperado de https://www.gob.mx/cms/uploads/attachment/file/94214/NOM006-CONAGUA-1997.pdf

Segob \& Salud, Secretaría de Gobernación \& Secretaría de Salud. (2019). NOM -127-SSA1-1994. Salud ambiental. Agua para uso y consumo humano. Límites permisibles de calidad y tratamientos a que debe someterse el agua para su potabilización. Recuperado de https://www.gob.mx/cms/uploads/attachment/file/110520/MODIF ICACION_A_LA_NORMA_NOM_127_SSA1_1994_22_NOVIEMBRE_ 2000.pdf

Sefotur \& UADY, Secretaría de Fomento Turístico \& Universida d Autónoma de Yucatán. (2013). Diagnóstico de competitividad y sustentabilidad de los pueblos mágicos. Municipio de Valladolid, Yucatán, México. Recuperado de http://www.sefotur.yucatan.gob.mx

Viñuales, V., Fernández, M., \& González, E. (2001). La ecoauditoría del agua. Zaragoza, España: Sansueña Industrias Gráficas, S.A. 